\title{
Validation of Tectonic Models for an Intraplate Seismic Zone, Charleston, South Carolina, with GPS Geodetic Data
}

Manuscript Completed: February 1997

Date Published: February 1997

Prepared by

P. Talwani, J. N. Kellogg, R. Trenkamp

University of South Carolina

Department of Geological Sciences

Columbia, SC 29208

E. G. Zurflueh, NRC Project Manager

Prepared for

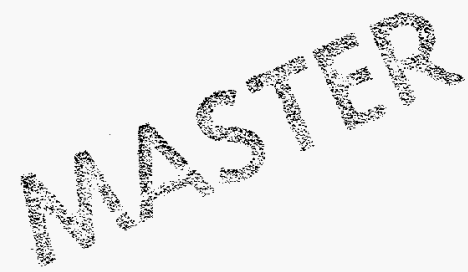

Division of Engineering Technology

Office of Nuclear Regulatory Research

U.S. Nuclear Regulatory Commission

Washington, DC 20555-0001

NRC Job Code G2519 


\section{DISCLAIMER}

Portions of this document may be illegible in electronic image products. Images are produced from the best available original document. 


\section{DISCLAIMER}

This report was prepared as an account of work sponsored by an agency of the United States Government. Neither the United States Government nor any agency thereof, nor any of their employees, make any warranty, express or implied, or assumes any legal liability or responsibility for the accuracy, completeness, or usefulness of any information, apparatus, product, or process disclosed, or represents that its use would not infringe privately owned rights. Reference herein to any specific commercial product, process, or service by trade name, trademark, manufacturer, or otherwise does not necessarily constitute or imply its endorsement, recommendation, or favoring by the United States Government or any agency thereof. The views and opinions of authors expressed herein do not necessarily state or reflect those of the United States Government or any agency thereof. 


\begin{abstract}
Although the average strain rate in intraplate settings is 2-3 orders of magnitude lower than at plate boundaries, there are pockets of high strain rates within intraplate regions.

The results of a Global Positioning System survey near the location of current seismicity (and the inferred location of the destructive 1886 Charleston, South Carolina earthquake) suggest that there is anomalous strain build-up occurring there. By reoccupying 1930 triangulation and 1980 GPS sites with six Trimble SST dual frequency receivers, a strain rate of $0.4 \times 10^{-7} \mathrm{yr}^{-1}$ was observed. At the $95 \%$ confidence level, this value is not significant; however, at a lower level of confidence $(\sim 85 \%)$ it is about two orders of magnitude greater than the background of $10^{-9}$ to $10^{-10} \mathrm{yr}^{-1}$. The direction of contraction inferred from the GPS survey $66^{\circ} \pm 11^{\circ}$ is in excellent agreement with the direction of the maximum horizontal stress $\left(\mathrm{N} 60^{\circ} \mathrm{E}\right)$ in the area, suggesting that the observed strain rate is also real.
\end{abstract}





\section{TABLE OF CONTENTS}

Abstract iii

Executive Summary $\ldots \ldots \ldots \ldots \ldots \ldots \ldots \ldots \ldots \ldots \ldots \ldots \ldots \ldots \ldots \ldots \ldots \ldots \ldots$

1. Introduction $\ldots \ldots \ldots \ldots \ldots \ldots \ldots \ldots \ldots \ldots \ldots \ldots \ldots \ldots \ldots \ldots \ldots \ldots$

2. Continuing Seismicity in the MPSSZ $\ldots \ldots \ldots \ldots \ldots \ldots \ldots \ldots \ldots \ldots \ldots$

2.1 Problem and Models $\ldots \ldots \ldots \ldots \ldots \ldots \ldots \ldots \ldots \ldots \ldots \ldots \ldots \ldots \ldots$

2.2 Stresses and Seismicity in Eastern North America ............. 5

2.3 Stresses and Seismicity in Southeastern United States ........... 9

2.4 Intersection Model for Intraplate Earthquakes . . . . . . . . . . . . 12

2.5 Localized Strain in the Mid-Lower Crust $\ldots \ldots \ldots \ldots \ldots \ldots \ldots$

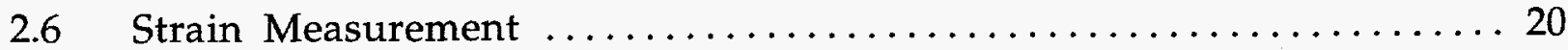

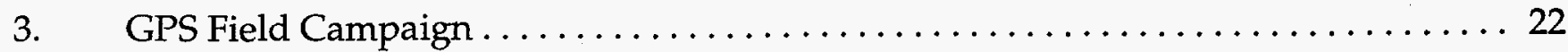

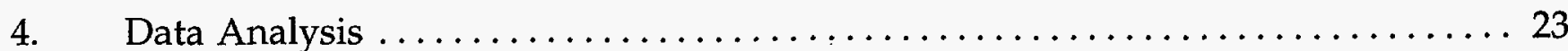

5. $\quad$ Results $\ldots \ldots \ldots \ldots \ldots \ldots \ldots \ldots \ldots \ldots \ldots \ldots \ldots \ldots \ldots \ldots \ldots \ldots \ldots$

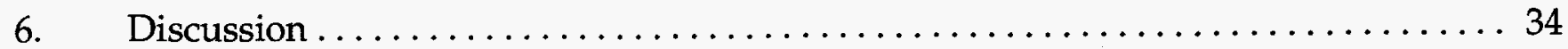

References .................................. 36

Appendix - Solution Strategy Developed by Jeff Freymueller for GPS Data Processing Using GIPSY-OASIS II Software 


\section{LIST OF FIGURES}

Figure 1. Decay in the frequency of earthquakes following the 1886 mainshock. The line through the data represents a value of $p=1.0$. Note that seismicity occurring subsequent to 1892 falls well above this line, suggesting that it is independent of the 1886 event ........ 4

Figure 2. Station locations of the South Carolina Seismic Network in the Coastal Plain. Data are recorded at Charleston Southern University near station BCS and at the University of South Carolina at Columbia. ................................6

Figure 3. North American plate stress directions $\ldots \ldots \ldots \ldots \ldots \ldots \ldots \ldots$

Figure 4. (A) Stress map of eastern United States and southeasternmost Canada showing the directions of maximum horizontal compressive stress. Data points within area enclosed by the polygon on the stress map are shown in the histogram (B) below comparing relatively shallow in situ indicators with earthquake focal plane mechanisms. Note that the mean and standard deviation of both sets of data are essentially identical $\ldots \ldots \ldots \ldots \ldots \ldots \ldots \ldots \ldots \ldots$

Figure 5. Seismic activity in the southeastern United States between 1978 and 1984. $A A^{\prime}$ is the profile along which the stress was computed. . . . . . 10

Figure 6a. The principal stresses for a cross-section of the lithosphere along

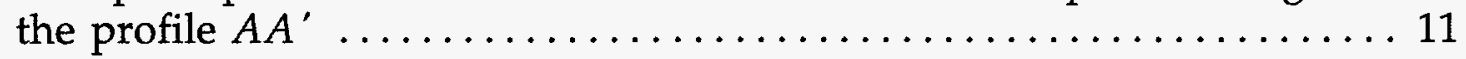

Figure 6b. The principal stress differences along the same profile. Contour

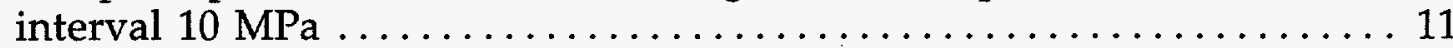

Figure 7. New layered velocity model compared with old gradient model ...... 13

Figure 8a. Epicentral locations (solid circles) obtained with new velocity model. Hypocenters in groups A, B and C are shallower than $8 \mathrm{~km}$; those in $\mathrm{D}$ are deeper. Composite focal plane solutions for each group are shown on sides-thrust faulting for shallower events, with rightlateral strike-slip fault for deeper set. Lower focal hemispheres are shown; pattern indicates compressional quadrants; heavy lines indicate preferred nodal planes. Inferred $\mathrm{P}$ axes for all solutions (solid dots; composited in projection below that for $\mathrm{D}$ ) are in $\mathrm{N} 60^{\circ} \mathrm{E}$ $\mathrm{S} 60^{\circ} \mathrm{W}$ direction. J=Jedburg, $\mathrm{SV}=$ Summerville, $\mathrm{W}=$ Woodstock, 
MP=Middleton Place, $\mathrm{AR}=$ Adams Run, $\mathrm{R}=$ Ravenel, $\mathrm{RA}=$ Rantowles. $E^{*}$ represents Dutton's (1889) epicenters. . . . . . . . . . . . . . . 14

Figure 8b. East - West cross-section along lat $33^{\circ} \mathrm{N}$ in a. Only earthquakes north of lat $32^{\circ} 55^{\prime} \mathrm{N}$ have been included.

Figure 9. Locations of instrumentally recorded seismicity (1974-1980) in the Charleston area of South Carolina. The Ashley River Fault (ARF) and the Woodstock Fault (WF) are associate with thrust and strike slip faulting respectively. Arrows indicate the direction of $S_{H \max } \ldots \ldots 15$

Figure 10. Stress distribution from a photoelastic experiment on intersecting fractures in rock under uniaxial loading. Regions at ends of fractures are locked. Numbered contours are presumed to represent isochromatic fringes of constant shear stress $\ldots \ldots \ldots \ldots \ldots \ldots \ldots . .17$

Figure 11. Schematic diagram showing the relative motion of blocks related to two intersecting faults. If the main fault undergoes strike slip motion, the adjoining block moves down due to kinematic adjustment. The large arrows represent the direction of $\mathrm{S}_{\mathrm{Hmax}} \ldots \ldots \ldots 18$

Figure 12. Least-stress gradient contour map for south-central Oklahoma showing major geologic features and the contemporary seismicity. Shaded area is where the least-stress gradient equals or exceeds $1.0 \mathrm{psi} / \mathrm{ft}(0.023 \mathrm{MPa} / \mathrm{m})$. Solid arrows represent the average direction of $\mathrm{S}_{\mathrm{Hmax}}$ as inferred from borehole breakout data in the Anadarko basin and Marietta basin areas .................... 19

Figure 13. Model of a vertical strike-slip fault in the upper crust which is driven by localized ductile strain in the lower crust ............. 21

Figure 14. Final twenty station grid containing both 1930 s and 1980 s stations . . . 24

Figure 15. Triangulation and GPS network to be used in the strain analysis around Middleton Place.

Figure 16. The total campaign: Each color represents one day of the campaign and shows baselines measured during that day. Baselines measured between continuously occupied stations and daily sessions are not displayed for clarity but it should be realized that these measurements add eight baseline measurements per session day and eighty baseline measurements throughout the campaign .............. 26 
Figure 17a. Half campaign: For the sake of clarity, half of the campaign is recreated here and in Figure $17 \mathrm{~b}$. As before, each color represents one day of the campaign and shows baselines measured during that day

Figure 17b. Half campaign: For the sake of clarity, half of the campaign is recreated here and in Figure 17a. As before, each color represents one day of the campaign and shows baselines measured during that day

Figure 18. Tracking stations used in Charleston GPS project analysis . . . . . . 30

Figure 19. Residuals for intersite GPS vectors from a minimally constrained adjustment of these data. Residuals are plotted as a function of intersite distance from Waltport $\ldots \ldots \ldots \ldots \ldots \ldots \ldots \ldots \ldots \ldots . \ldots \ldots$ 


\section{LIST OF TABLES}

Table 1. Pre-1886 South Carolina Earthquakes $\ldots \ldots \ldots \ldots \ldots \ldots \ldots \ldots \ldots$

Table 2. Number of Observations by Decade $\ldots \ldots \ldots \ldots \ldots \ldots \ldots \ldots \ldots \ldots$

Table 3. Strain in ppm and Angle of Maximum Contraction Clockwise

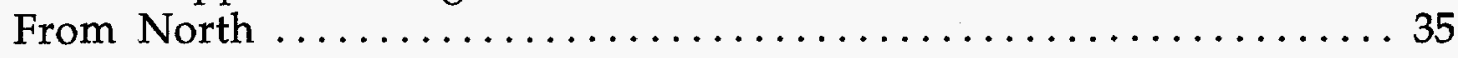





\section{EXECUTIVE SUMMARY}

Although destructive earthquakes are rare in intraplate settings, they are responsible for a disproportionate amount of damage as they are often located in highly populated areas. Compared to plate boundaries, the rates of strain accumulation within plates are significantly lower. Based on average seismic moment release in central and eastern United States, Anderson (1986) estimated the rates of average strain accumulation to be $10^{-11}$ to $10^{-12} \mathrm{yr}^{-1}$ except near historical sites of large intraplate earthquakes. Estimates of strain accumulation rates from plate reconstruction misfit range from $2 \times 10^{-9}$ to $2 \times 10^{-10} \mathrm{yr}^{-1}$ and from plate velocity closure error from Very Long Baseline Interferometry and Satellite Laser Ranging 3 x 10-10 $\mathrm{yr}^{-1}$ (Morgan, 1988).

The results of paleoseismic investigations in South Carolina have revealed the occurrence of at least six pre-1886 earthquakes capable of causing widespread liquefaction $(M>6.0)$. The estimated recurrence times 500-1000 years, argue for considerably faster rates of strain accumulation near Charleston, i.e., for localized pockets of high strain rate accumulation surrounded by low rates over the surrounding background (Section 1).

Of the various models suggested to explain the occurrence of intraplate earthquakes and the ongoing seismicity (Section 2), the intersection model, (Talwani, 1988) can explain localized strain accumulation. In order to test the applicability of the intersection model it was decided to measure localized strain build-up near Charleston.

Liu and others (1992) had shown that by reoccupying old triangulation sites with modern Global Positioning System (GPS) it was possible to measure localized strain build-up in an intraplate setting.

With the help of the South Carolina Geodetic Survey, several triangulation stations from a 1930 survey and some GPS stations from a 1980 survey were identified for reoccupation by GPS receivers (Section 3). Eventually 20 sites were selected. They surround the current seismicity near Charleston (and the inferred source of the 1886 earthquakes). The GPS campaign was carried out in December 1993 and January 1994 using 6 Trimble SST dual frequency receivers. Eleven individual observation sessions averaging six hours were scheduled to coincide with the time of day for the optimal satellite constellation geometry for measuring relative position among the stations. The eleven observation days allowed for each station to be observed at least twice with two stations, Waltport and Sewee 2 RMA which were occupied continuously throughout the campaign. 
The data were processed at the University of South Carolina using software obtained from JPL/NASA, National Geodetic Survey, UNAVCO and Stanford University (Section 4).

Maximum shear strain rate was estimated by the simultaneous reduction method (Section 5). A value of $0.041 \pm 0.017 \mu$ strain/yr with a direction of maximum contraction $66^{\circ} \pm 11^{\circ}$ was obtained. The direction of maximum contraction $\mathrm{N} 66^{\circ} \mathrm{E} \pm 11^{\circ}$ agrees very well with inferred direction of $\mathrm{S}_{\mathrm{Hmax}}, \mathrm{N} 60^{\circ}$ $\mathrm{E}$ for the area. The strain accumulation rate at the $95 \%$ confidence level does not differ significantly from zero. At a lower confidence rate, the strain accumulation rate of $0.4 \times 10^{-7} \mathrm{yr}^{-1}$ is about two orders of magnitude larger than the average background rate of $10^{-9}-10^{-10} \mathrm{yr}^{-1}$. The observation that the direction of contraction obtained from the GPS survey agrees so well with $S_{H \max }$ strongly suggests that the anomalously high observed strain rates are real. Additional data during a later GPS campaign, reoccupying the GPS sites of 1993-1994 will confirm and strengthen these initial results which were based on reoccupying several triangulation sites with GPS measurements. 


\section{Introduction:}

Elastic strain energy accumulation rates determine the frequency of large earthquake occurrence. Anderson (1986) estimated typical strain rates from seismic strain release for the entire Central and Eastern United States stable continental crust to be on the order of $10^{-11}$ to $10^{-12} \mathrm{yr}^{-1}$ except near historical sites of large intraplate earthquakes, while estimates from plate reconstruction misfit or plate velocity closure error range from $\sim 2 \times 10^{-9}$ to $2 \times 10^{-10}$ to $3 \times 10^{-10} \mathrm{yr}^{-1}$ from VLBI (Very Long Baseline Interferometry) and SLR (Satellite Laser Ranging) (Morgan, 1988) as quoted by Johnston (1989). In areas such as the New Madrid, Missouri and Charleston, South Carolina seismic zones, relatively rapid strain accumulation is indicated by paleoseismic evidence of high energy release earthquakes every 500 - 1000 years (Amick and Gelinas, 1991; Saucier, 1991).

Historically, reports of felt earthquakes in the Charleston South Carolina area date back to 1698 (Bollinger and Visvanathan, 1977) (Table 1). On August 31, 1886 the largest historical earthquake in the eastern United States occurred near Charleston South Carolina. Although not as large as the 1811 - 1812 New Madrid Missouri events. This Modified Mercalli Intensity X (M 7.4) (Bollinger, 1977; Johnston, 1996) earthquake occurring in close proximity to populated areas made it the most destructive U.S. earthquake in the 19th century and the only earthquake east of the Rocky Mountains known to have caused loss of life in the United States.

Paleoseismic evidence of large prehistoric earthquakes along the Atlantic seaboard suggests that large earthquakes $\left(m_{b}=5.8 \pm 0.4\right)$ may have been restricted exclusively to South Carolina. Paleoliquefaction evidence for at least 5 of the 6 large prehistoric earthquakes indicate an origin near the locale of the 1886 Charleston, South Carolina event with a recurrence rate during the past two millennia of approximately 500 - 600 years (Amick and Gelinas, 1991). Although the paleoseismic record extends beyond 2000 YBP, Amick and Gelinas (1991) contend that the record is only intermittent between $2000-5000 \mathrm{YBP}$ and extremely limited for earlier than 5000 YBP.

Previous studies in the New Madrid Seismic Zone (NMSZ) (Liu et al., 1992) (Liu, 1994) (Snay et al., 1993) used GPS (Global Positioning System) measurements and preexisting geodetic measurements to determine strain accumulation in an intraplate setting. Liu et al., (1992) determined annual shear strain to be accumulating across the southern NMSZ at a rate of $\sim 1 \mu$ strain at a $95 \%$ confidence while in the northern NMSZ, Snay et al., (1993) estimated a strain that does not statistically differ from zero. 


\section{Table 1. \\ Pre-1886 South Carolina Earthquakes}

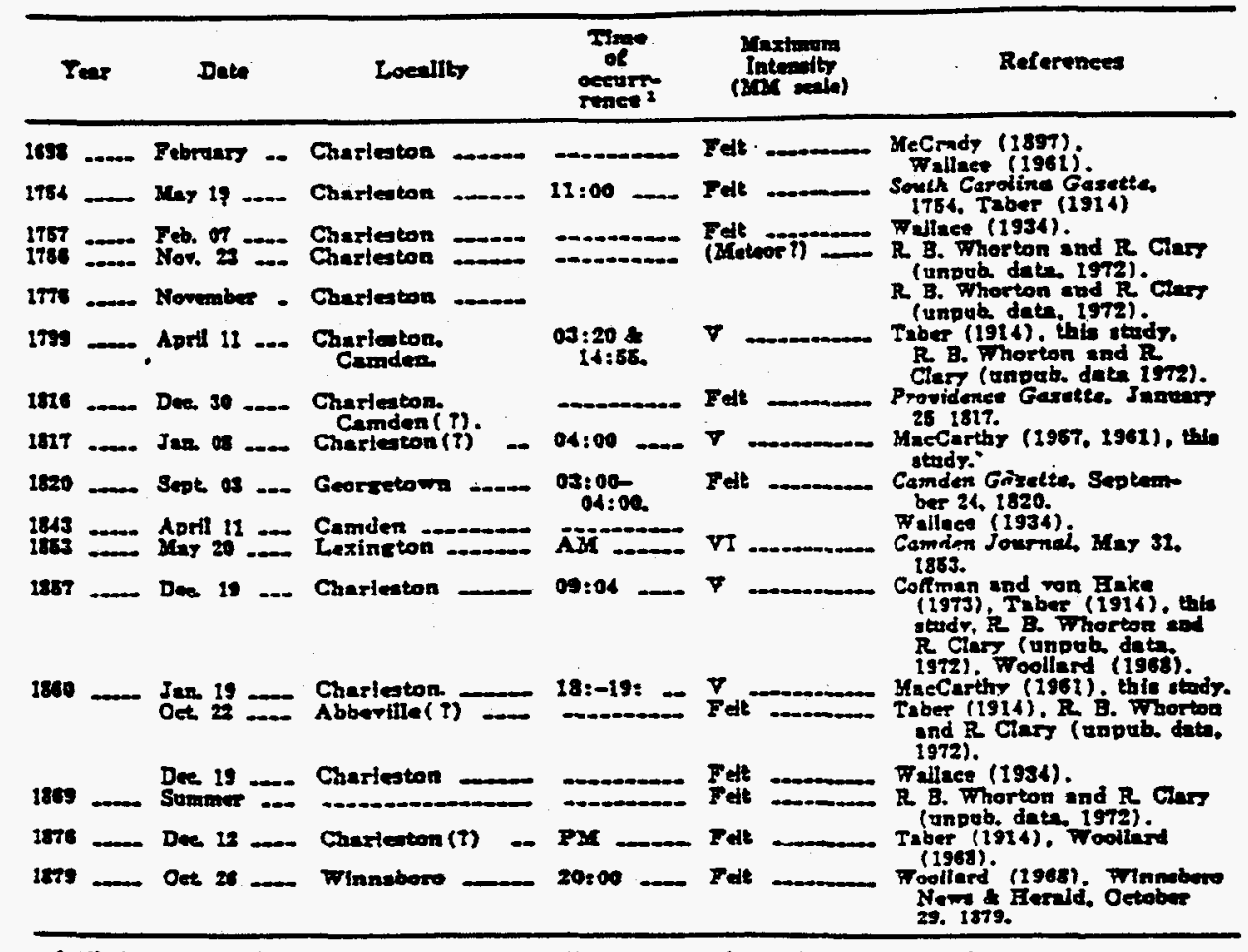

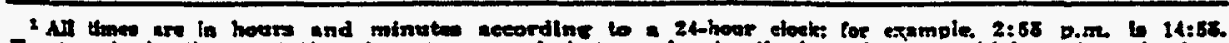

These observations suggested that it may be possible to measure strains at Charleston, the location of the 1886 earthquake and ongoing seismic activity. In the epicentral area of the 1886 Charleston earthquake, several preexisting geodetic surveys cross the inferred epicentral tract of the 1886 earthquake. Many of the monumented sites are still available and suitable for GPS measurements. Similar to the studies done in the NMSZ, optimally distributed GPS monitoring using a densely spaced array and the preexisting geodetic data should give a first approximation of the shear strain accumulation rates in the epicentral area of the 1886 event.

The center of the study area for this study is located about $20 \mathrm{~km}$ northwest of Charleston and is the most active seismic zone in South Carolina. Today this area is referred to as the Middleton Place Summerville Seismic Zone (MPSSZ) (Tarr, et al., 1981). The MPSSZ is a diffuse zone of seismicity approximately 11 $\mathrm{km}$ by $14 \mathrm{~km}$ with the majority of the earthquakes located in a $5 \mathrm{~km}$ by $6 \mathrm{~km}$ zone (Madabhushi and Talwani, 1993). . The existence of a concentrated rather than a random area of seismicity leads to the conclusion of highly localized strain accumulation and therefore localized stress build-up within the ambient stress field. 
Talwani (1989a) listed four models in which localized stress build-up in the ambient stress field is the common feature. They are stress amplification near plutons (Long and Champion, 1977; Kane, 1977; Simmons et al., 1976; McKeown, 1978; Barstow et al., 1981), the "kinks" model (King and Nabelek, 1985; King, 1986), the intersection model (Talwani et al.,1979; Talwani, 1988; Illies, 1982) and localized strain in the mid-lower crust (Kunze, 1982; Zoback, 1983; Zoback et al., 1985). The two models which pertain more closely to the MPSSZ will be examined more closely later.

In Section 2, we will discuss the continuing seismicity and style of faulting in the MPSSZ along with the two models pertinent to the Charleston area, which may account for localized stress build-up. Also discussed in this section are the problems associated with the attempts to measure strain in the epicentral area of the 1886 Charleston earthquake and a general discussion of the use of GPS and triangulation data to measure strain accumulation. Section 3 will describe the planning and execution of the GPS campaign in December 1993 and January 1994. Section 4 details the GPS and triangulation data analysis techniques using GIPSYOASIS II and DYNAP software packages. Section 5 reports the results of the data analysis and the interpretation of those results.

\section{Continuing Seismicity in the MPSSZ:}

Although it has been suggested that most of the Charleston area earthquakes felt and recorded since 1886 are aftershocks of the 1886 event (Bollinger, 1983); Talwani (1983) and Amick and Talwani (1986) determined that the logarithmic decay in the frequency of earthquakes following the 1886 event lasted only through 1892 and that subsequent seismicity appears to represent a new seismic cycle independent of the 1886 shock (Figure 1). If this were not true, the earthquake frequency - intensity distribution of the last 100 years may not be representative of long term frequency distribution of earthquakes in the area. That would then negate the assumption of frequency - intensity distribution linearity and hence its use as a recurrence interval estimator for large events. The continuing seismicity in South Carolina from 1698 to 1975 was garnered from newspaper accounts and meteorological station reports and published in a list of felt events compiled by Taber (1914) Bollinger (1972, 1975) and Visvanathan (1980).

Seismic network monitoring began in South Carolina with a reconnaissance field survey in March of 1973 in the meizoseismal zone of the 1886 earthquake (Tarr and King, 1974). This survey was followed by the establishment of a permanent statewide network in May of 1974 (Tarr, 1977). The present configuration of the Coastal Plain Seismic Network which monitors the epicentral area of the 1886 event consists of 12 stations. It is at present undergoing 


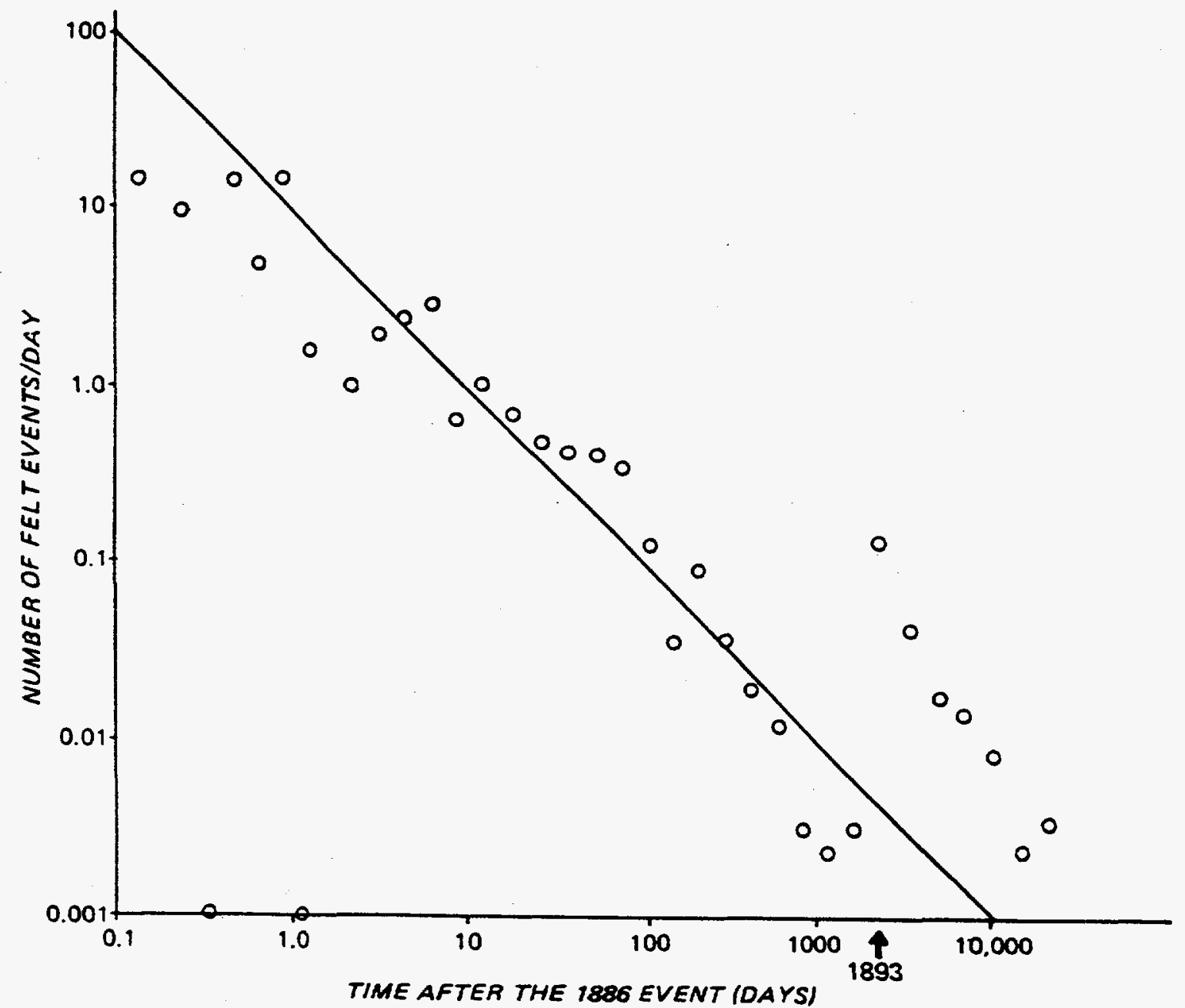

Figure 1. Decay in the frequency of earthquakes following the 1886 mainshock. The line through the data represents a value of $p=1.0$. Note that seismicity occurring subsequent to 1892 falls well above this line, suggesting that it is independent of the 1886 event.

(Modified From Amick and Talwani, 1986). 
intensive reconfiguration in order to detect more completely the extent of the microseismicity connected to the strain accumulation in the MPSSZ (Talwani et al., 1995) (Figure 2).

\subsection{Problem and Models:}

The major problem to be resolved is how are stresses concentrated or focused to create large strain accumulations in localized areas within plates, when the platewide strain rates are so consistently small. Regional stress patterns globally are generated by broad scale plate tectonics forces. These tectonic stresses include plate boundary forces which either drive or resist plate motion (Zoback et al., 1989). Measurement of these stresses is accomplished using various techniques which are discussed in some detail in McGarr and Gay (1978) and Zoback and Zoback (1991).

Turcotte (1984) hypothesized that the seismicity of eastern North America is not due to active tectonics as would be the case for an Andean type margin but rather is due to the relatively high level of stress in the plate interiors. These stresses are, as mentioned previously generated in the main by plate tectonic forces. Forsyth and Uyeda (1975) and Richardson, et al., (1979) categorized these forces as (1) Ridge Forces, (2) Subduction Zone Forces (slab pull), (3) Drag Forces, (4) Transform Fault Forces. According to Richardson and Cox (1984) only two of the possible forces associated with the driving mechanism for plate tectonics are candidates as a source of stress... ridge push and basal drag. Slab forces were dismissed because the North American plate has essentially no slab attached to it and transform fault forces are unimportant either because they are small or the intervening Basin and Range isolates eastern North America from them. Turcotte (1984) also added stresses associated with lithospheric flexure as possibly being important, particularly along the east coast of the United States.

\subsection{Stresses and Seismicity in Eastern North America:}

Zoback and Zoback (1991) characterized the stresses of the stable interior of North America as equivalent to the Midplate stress province that dominates most of Canada, the central and eastern United States and most of the western Atlantic. The relatively uniform east-northeast direction of maximum horizontal compression over an extremely large area and a consistent characteristic of the Midplate stress province (Figures 3 and 4). The faulting styles as noted are also regionalized with a general north/south or Canada/United States regional separation, with predominantly reverse faulting in Canada and predominantly strike slip faulting in the United States (Talwani and Rajendran, 1991). Therefore, it can be stated that, at seismogenic depths with relatively few exceptions, the relative magnitudes of the principal stresses are SHmax $>$ Shmin $>$ 


\section{Coastal Plain Seismic Network}

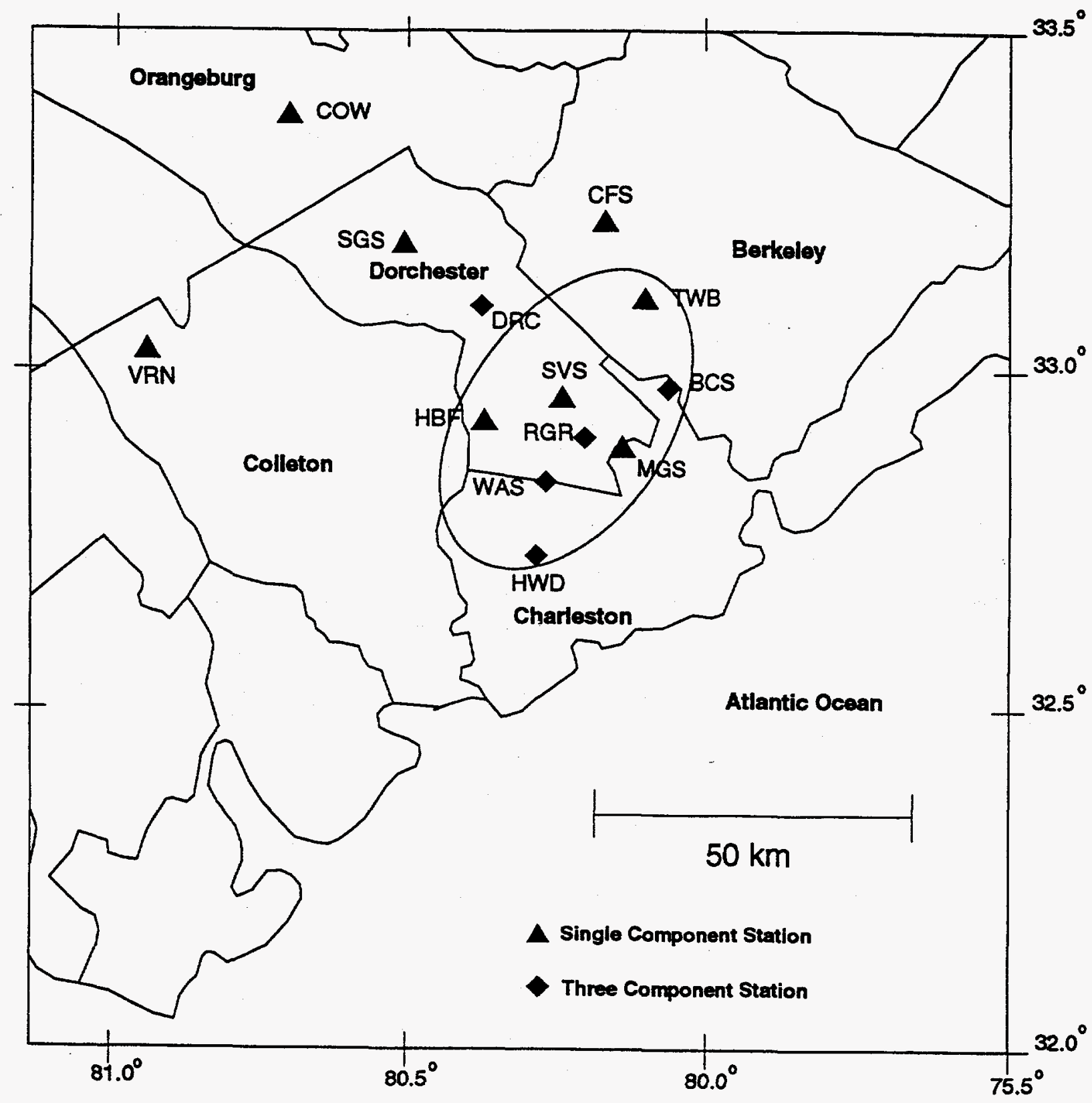

Figure 2. Station locations of the South Carolina Seismic Network in the Coastal Plain. Data are recorded at Charleston Southern University near station BCS and at the University of South Carolina at Columbia. 


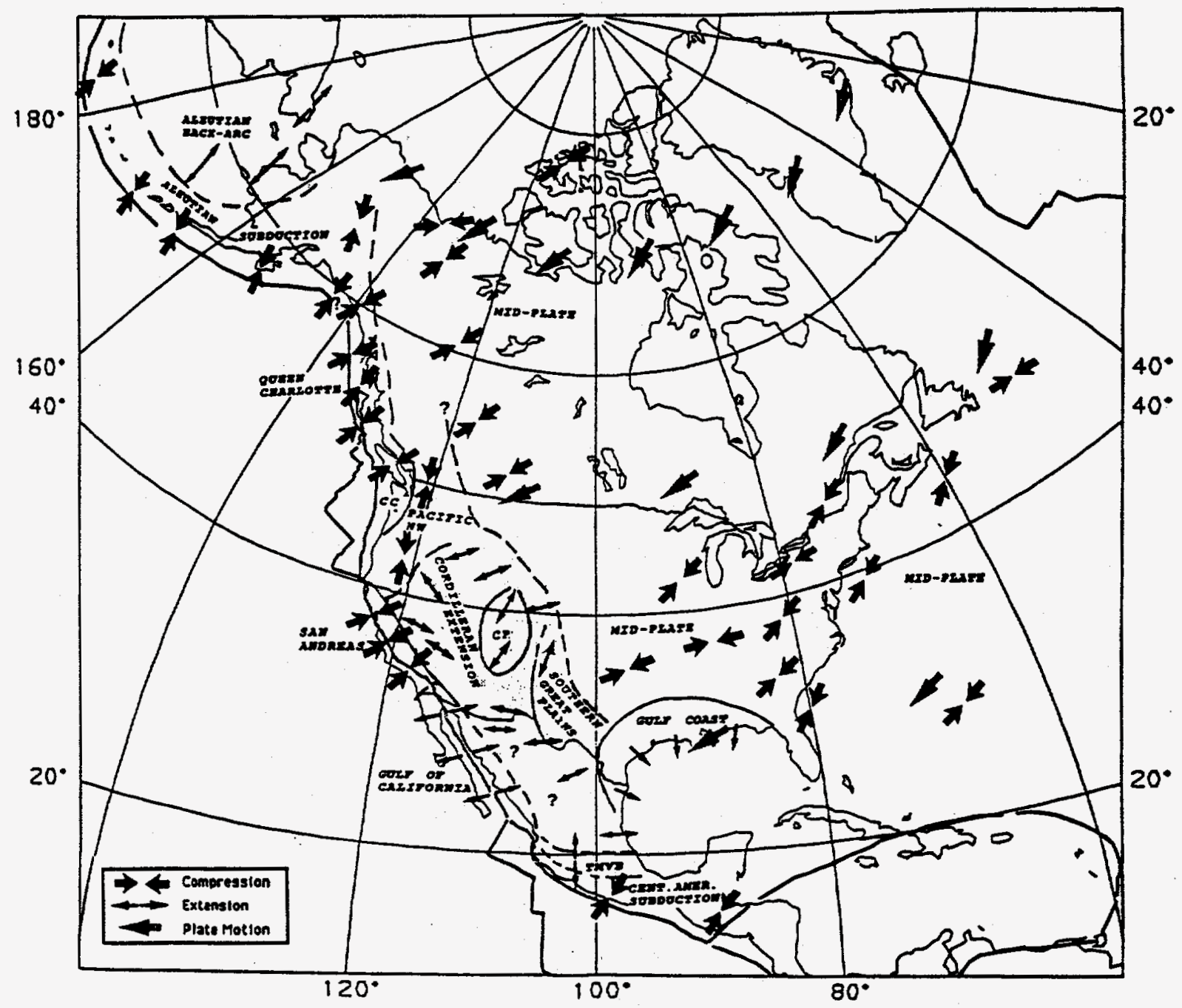

Figure 3. North American Plate stress directions.

(Modified From Zoback and Zoback, 1991). 

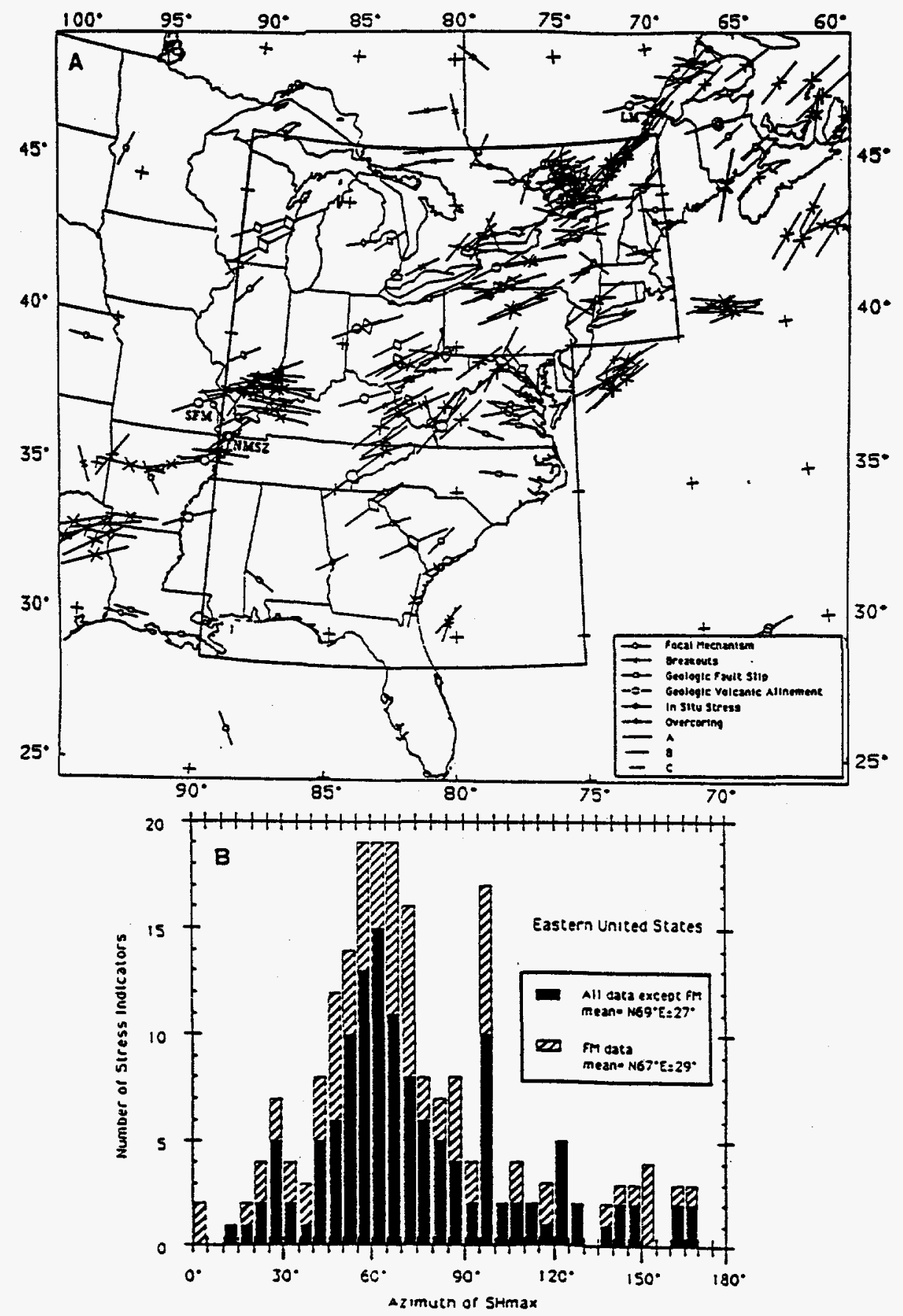

Figure 4. (A) Stress map of eastern United States and southeasternmost Canada showing the directions of maximum horizontal compressive stress. Data points within area enclosed by the polygon on the stress map are shown in the histogram (B) below comparing relatively shallow in situ indicators with earthquake focal plane mechanisms. Note that the mean and standard deviation of both sets of data are essentially identical.

(Modified From Zoback and Zoback, 1991). 
$\mathrm{S}_{\mathrm{v}}$ in southeastern Canada and $\mathrm{SH}_{\max }>\mathrm{Sv}>\mathrm{Sh}_{\min }$ in the central and eastern United States.

Zoback (1992), in a study using well constrained focal mechanisms of thirty-two midplate earthquakes $\left(m_{b}=3.8-6.5\right)$ to determine if slip is compatible with the broad scale regional (NE - SW) stress derived from plate driving forces, concluded that a majority of the earthquakes (25 of 32) was found to be geometrically compatible with the reactivation of favorably oriented preexisting fault planes in response to said regional stress field. Slip in five events was found to be clearly inconsistent with the regional stress field and appeared to require a localized stress anomaly to explain the seismicity. Three focal mechanisms that had slip vectors geometrically consistent with the regional stress fields were at such an extreme angle as to require an extremely low coefficient of friction or pore pressures far exceeding the least principal stress.

\subsection{Stresses and Seismicity in Southeastern United States:}

Seismicity in the southeastern United States, is concentrated in four areas, eastern Tennessee and southwestern North Carolina, central Virginia, Giles County Virginia and the Charleston, South Carolina area. Several studies (Talwani, 1986, 1989b) and (Bollinger et al., 1991) attempted an understanding of the seismicity and stresses of these areas. Mareschal and Kuang (1987) and Kuang et al., (1989) computed the stresses induced by topography and density heterogeneities in the lithosphere for the eastern Tennessee and Charleston seismic regions (Figure 5). In the southern Appalachians, the topographic load and lateral density inhomogeneity in the lithosphere produced a stress on the order of $50 \mathrm{MPa}$ (Figure 6). The correlation of the southern Appalachian seismicity with the local stress field suggested that the mass anomalies could play a role in triggering the earthquakes in eastern Tennessee and western North Carolina. Long and Zelt (1991) suggested that the combination of these mass anomalies with inferred local weakening of the brittle-ductile transition zone would concentrate stress in the stronger elastic crust around and above the zone of decreased strength. This led Kuang et al., (1989) to conclude that in the southern Appalachians, the regional stresses are less important than the local stresses in causing earthquakes. In their models, in the Charleston area, the stress induced by the crustal density changes showed no correlation to the seismicity (Figure 6). These calculations do not predict any stress anomaly in the Charleston area. This may be because local structures and fault systems play a more important role in triggering earthquakes in the Charleston seismotectonic area (Talwani 1982).

Talwani (1982) used an improved velocity model for the meizoseismal area of the 1886 Charleston earthquake and used it to relocate the then current seismicity 


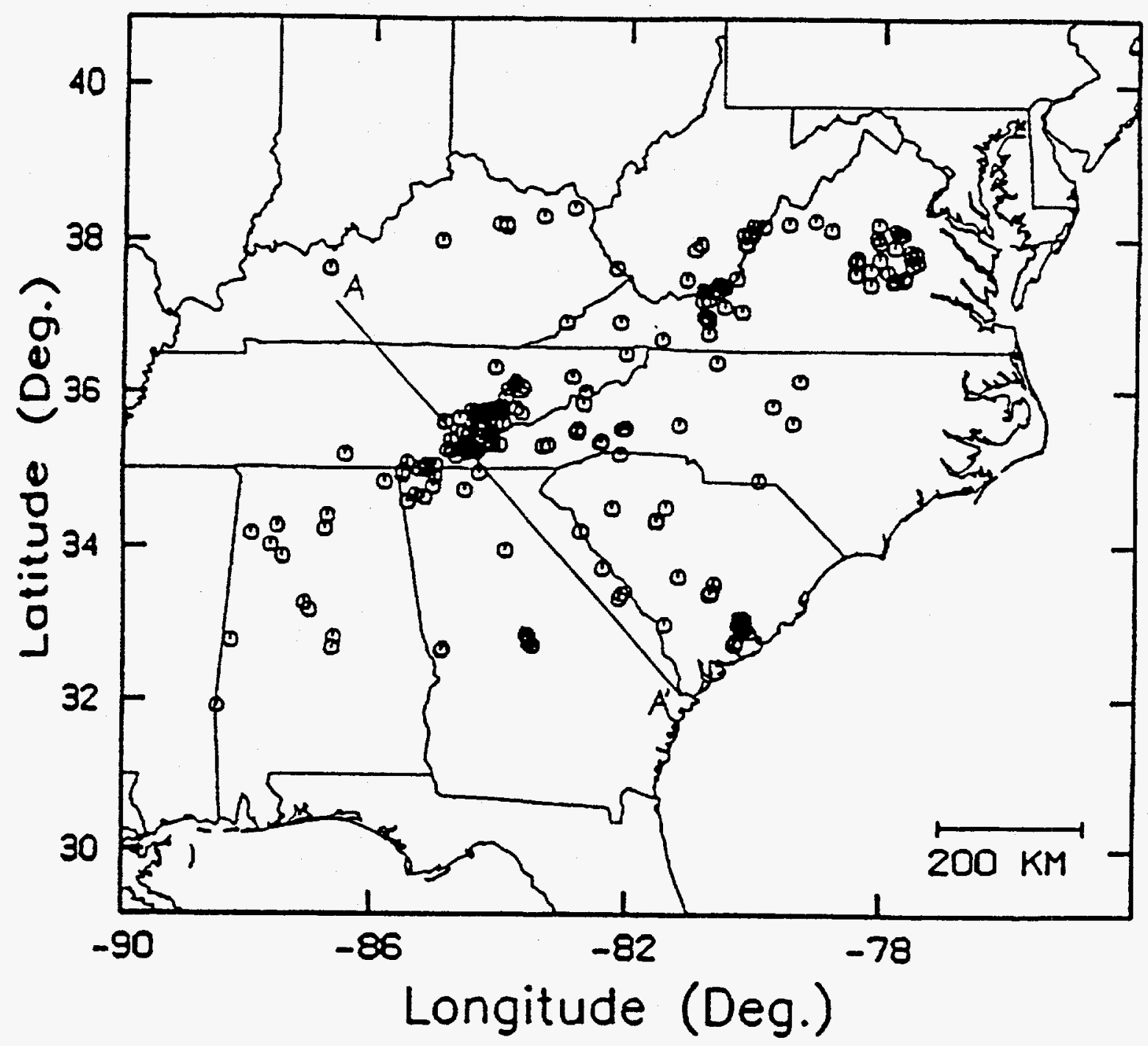

Figure 5. Seismic activity in the southeastern United States between 1978 and 1984. $A A^{\prime}$ is the profile along which the stress was computed.

(Modified From Mareschal and Kuang, 1987). 

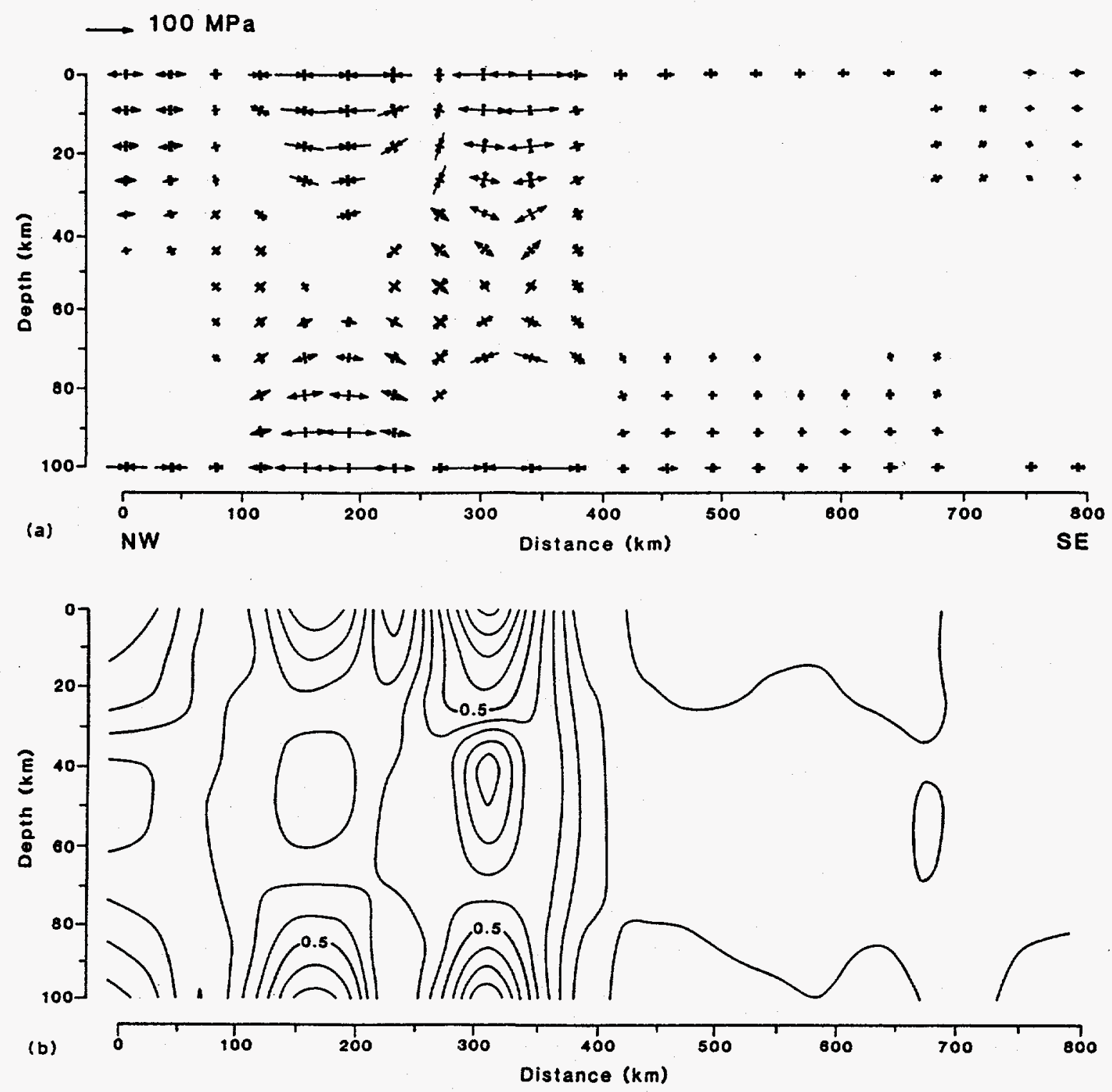

Figure 6a. The principal stresses for a cross-section of the lithosphere along the profile $A A^{\prime}$.

Figure 6b. The principal stress differences along the same profile. Contour interval $10 \mathrm{MPa}$.

(From Mareschal and Kuang, 1987). 
that had been recorded since the installation of the 10 station South Carolina Seismic Network. The new velocity model took into account lateral heterogeneity to improve travel time residuals and thus locate hypocenters more accurately (Figure 7). The results based on twenty seven well constrained events when compared to those of Rhea (1981) and Tarr, et al., (1981) showed a marked clustering of the hypocenters (Figure $8 \mathrm{a}$ and $\mathrm{b}$ ).

Talwani (1982) concluded that a consistency of composite fault plane solutions, hypocentral location patterns and the inferred P-axes implied a coherent deformation pattern which led to the separation into two seismic source zones at different depths and along differently oriented faults. The shallower set of earthquakes with hypocentral depths between 4 and $8 \mathrm{~km}$ are associated with high angle reverse faulting and is collinear with the seismicity along a segment of the Ashley River, called the Ashley River Seismogenic Zone. The deeper north - northeast striking Woodstock Fault is associated with right lateral strike slip movement (Figures 8b and 9). Madabhushi and Talwani (1993) using more precise relocations of MPSSZ earthquakes between 1980 and 1991 noticed a distinct clustering in a narrow $5 \mathrm{~km}$ by $6 \mathrm{~km}$ zone. They noted that this concentrated zone of seismicity included events that were associated with both the Ashley River fault zone and Woodstock fault and suggested that it defines the area of intersection of these two fault zones.

The question then really is why have large earthquakes occurred near Charleston in the past (Amick and Talwani, 1986) and why are they continuing to occur in the same area today? What can be causing the localization of seismicity in this area? Talwani (1989a) looked at the characteristic features of intraplate earthquakes and the models proposed to explain them and determined that the local stress build up and the reactivation of preexisting zones of weakness to be the underlying cause of seismicity in intraplate settings.

After reviewing the models that had been proposed to explain the occurrence of intraplate seismicity, including stress amplification near plutons (Long and Champion, 1977; McKeown, 1978; Kane, 1977; Campbell, 1978), the kinks model (King and Nabelek, 1985; King, 1986), localized strain in the mid-low crust (Kunze, 1982; Zoback,1983; Zoback et al., 1985) and the intersection model (Talwani, 1988), Talwani stated that "of all the models, I prefer the intersection model" which has many elements in common with or that complement the other models. Of all the models reviewed, the intersection model and the midcrustal-strain model are the only two possibly applicable to the Charleston area.

\subsection{Intersection Model for Intraplate Earthquakes:}

According to this model proposed to explain intraplate earthquakes (Talwani, et 


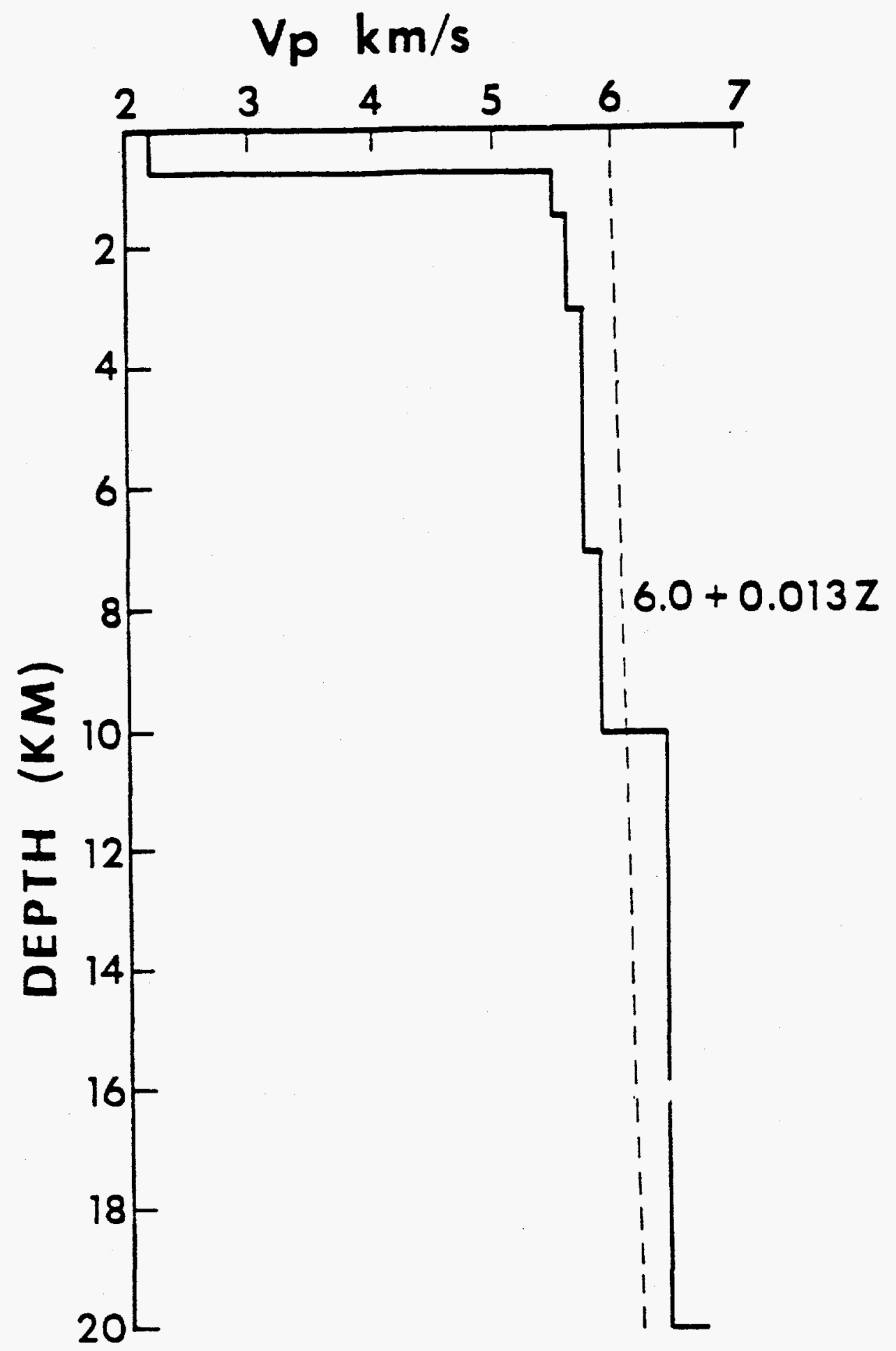

Figure 7. New layered velocity model compared with old gradient model (dashed line; Tarr and others, 1981). (From Talwani, 1982). 
a.

Charleston Earthquakes

$1974-1980$

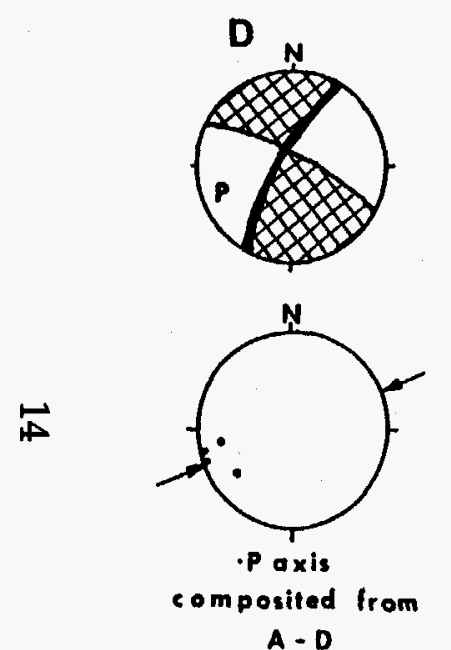

$A-D$

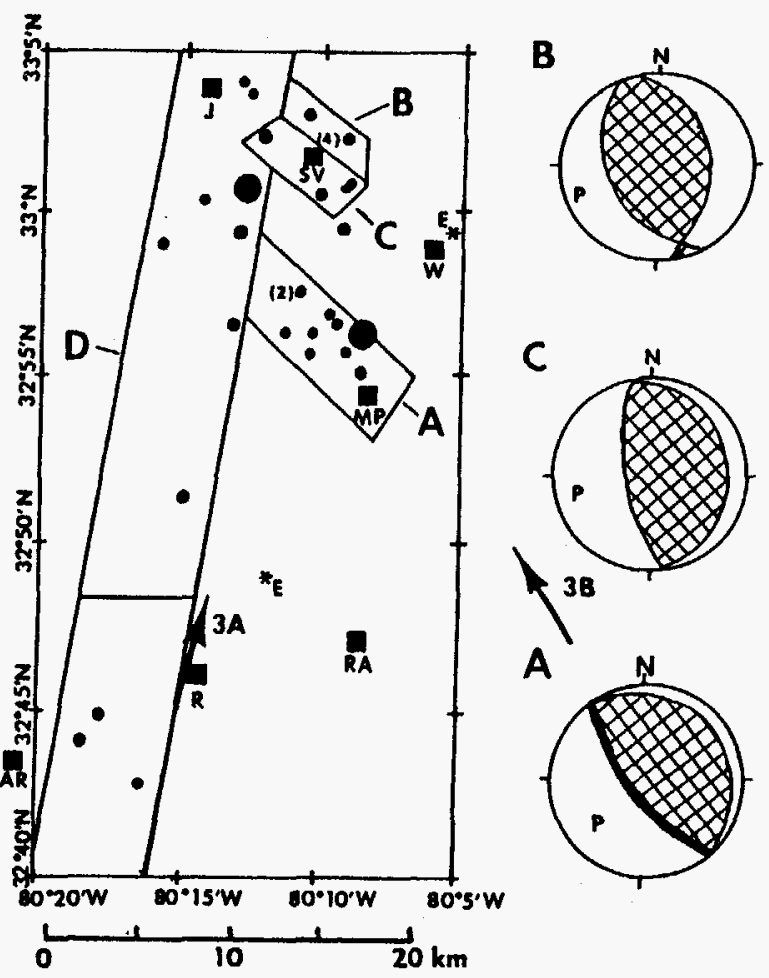

b.

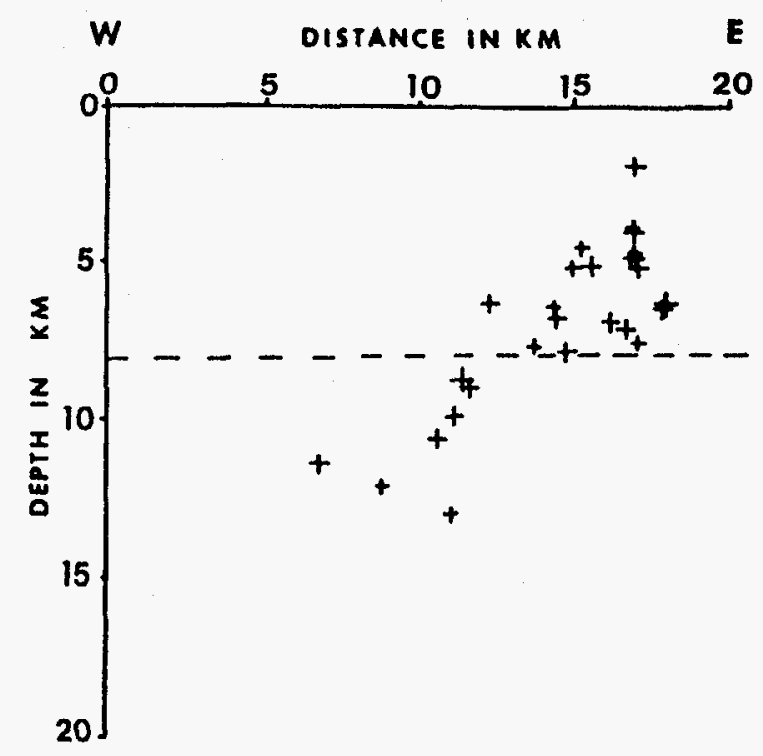

Figure 8a. Epicentral locations (solid circles) obtained with new velocity model. Hypocenters in groups A, B and C are shallower than $8 \mathrm{~km}$; those in D are deeper. Composite focal plane solutions for each group are shown on sides-thrust faulting for shallower events, with right-lateral strike-slip fault for deeper set. Lower focal hemispheres are shown; pattern indicates compressional quadrants; heavy lines indicate preferred nodal planes. Inferred $\mathrm{P}$ axes for all solutions (solid dots; composited in projection below that for $\mathrm{D}$ ) are in $\mathrm{N} 60^{\circ} \mathrm{E}-\mathrm{S} 60^{\circ} \mathrm{W}$ direction. $\mathrm{J}=\mathrm{Jedburg}, \mathrm{SV}=$ Summerville, $\mathrm{W}=$ Woodstock, $\mathrm{MP}=$ Middleton Place, AR=Adams Run, $R=$ Ravenel, RA=Rantowles. $E^{*}$ represents Dutton's (1889) epicenters.

(Modified From Talwani, 1982).

Figure 8b. East - West cross-section along lat $33^{\circ} \mathrm{N}$ in a. Only earthquakes north of lat $32^{\circ} 55^{\prime} \mathrm{N}$ have been included. 


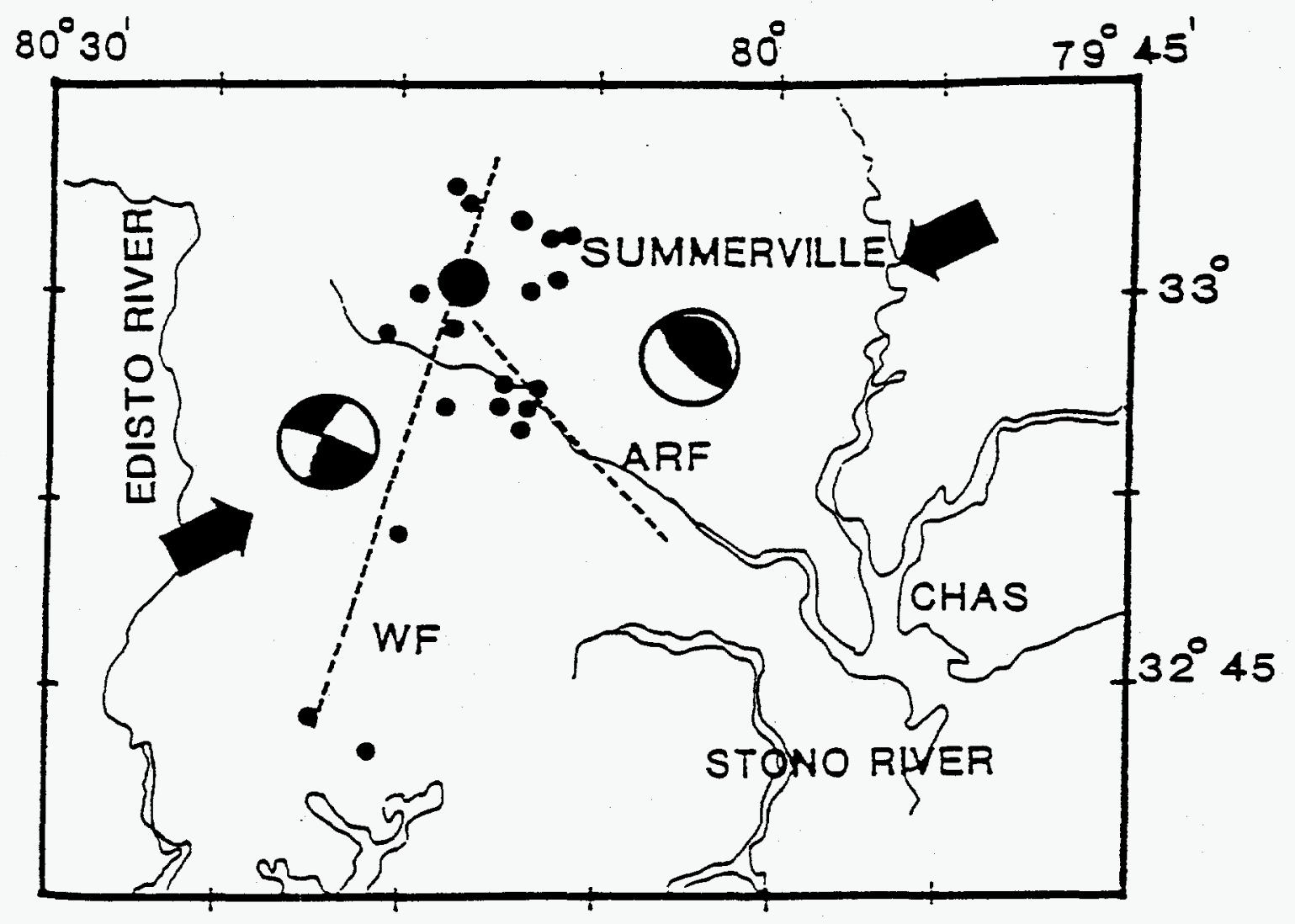

Figure 9. Locations of instrumentally recorded seismicity (1974-1980) in the Charleston area of South Carolina. The Ashley River Fault (ARF) and the Woodstock Fault (WF) are associate with thrust and strike slip faulting respectively. Arrows indicate the direction of $S_{\text {Hmax }}$.

(Modified From Talwani, 1986). 
al., 1979; Talwani, 1988, 1989a), the earthquakes lie at the intersection of preexisting zones of weakness. One of these zones of weakness is regional in scale, and may include fissures, breccias, hydrothermal veins etc. These are associated with sub-vertical discontinuities usually accompanied by or offsetting gravity and magnetic anomalies. The intersecting zone may be local in nature, e.g. the boundary fault of a buried basin, or it may be regional in scale, such as a major tectonic boundary or ancient suture zone. The vertical intersection which forms the boundary of crustal blocks forms the locus for the large earthquakes. The block boundaries often separate rocks with different rheological properties and are associated with increased density of fractures. The main event is usually associated with strike slip motion and lies on one of the intersecting features.

The intersections form the locked area of a fault and are the locations of stress build-up. Because movement on one fault is inhibited by the intersecting fault, stresses large enough to generate the major intraplate earthquake can build up at intersections. In the absence of intersections, the faults can slip at a lower threshold. Figure 10 is based on photoelastic experiments and shows how stresses can build up at the edges of intersecting faults. The stress build-up at the edges of intersecting faults is significantly greater than those at the ends of single non-intersecting faults. Intersections also help to localize the seismicity and as noted by King (1986), form the location where seismicity is initiated.

The faulting usually starts on one of the fault planes and due to the movement on it, triggers movement on the adjacent fault. In most cases of intraplate earthquakes strike slip faulting occurs on the main fault. The nature of movement on the second fault (Figure 11) can be vertical due to kinematic adjustments.

In a numerical model of two dimensional plane strain, Andrews (1989) found a bend in a fault acts as a barrier and leads to stress concentration. This stress concentration occurs at the bend and will tend to induce slip on the spur. Further, Andrews noted that, "a fault junction provides a natural realization of barrier and asperity models without appealing to arbitrary variations of fault strength."

Ellis (1991) demonstrated the validity of the model with in situ stress data from south central Oklahoma. Quoting from that study, "A contour map of leaststress gradients reported in a 1973 study of approximately 1500 hydraulically fractured oil wells in Oklahoma identifies an area in the south central part of the state magnitudes of least-stress, and thus also least horizontal stress, may be relatively higher in the surrounding region. The apparent high stress is in the area near the intersection of the west-northwest trending Wichita frontal fault system and the north-south trending McClain County fault zone, which is a possible southern extension of the Nemaha uplift (Figure 12). The Wichita 


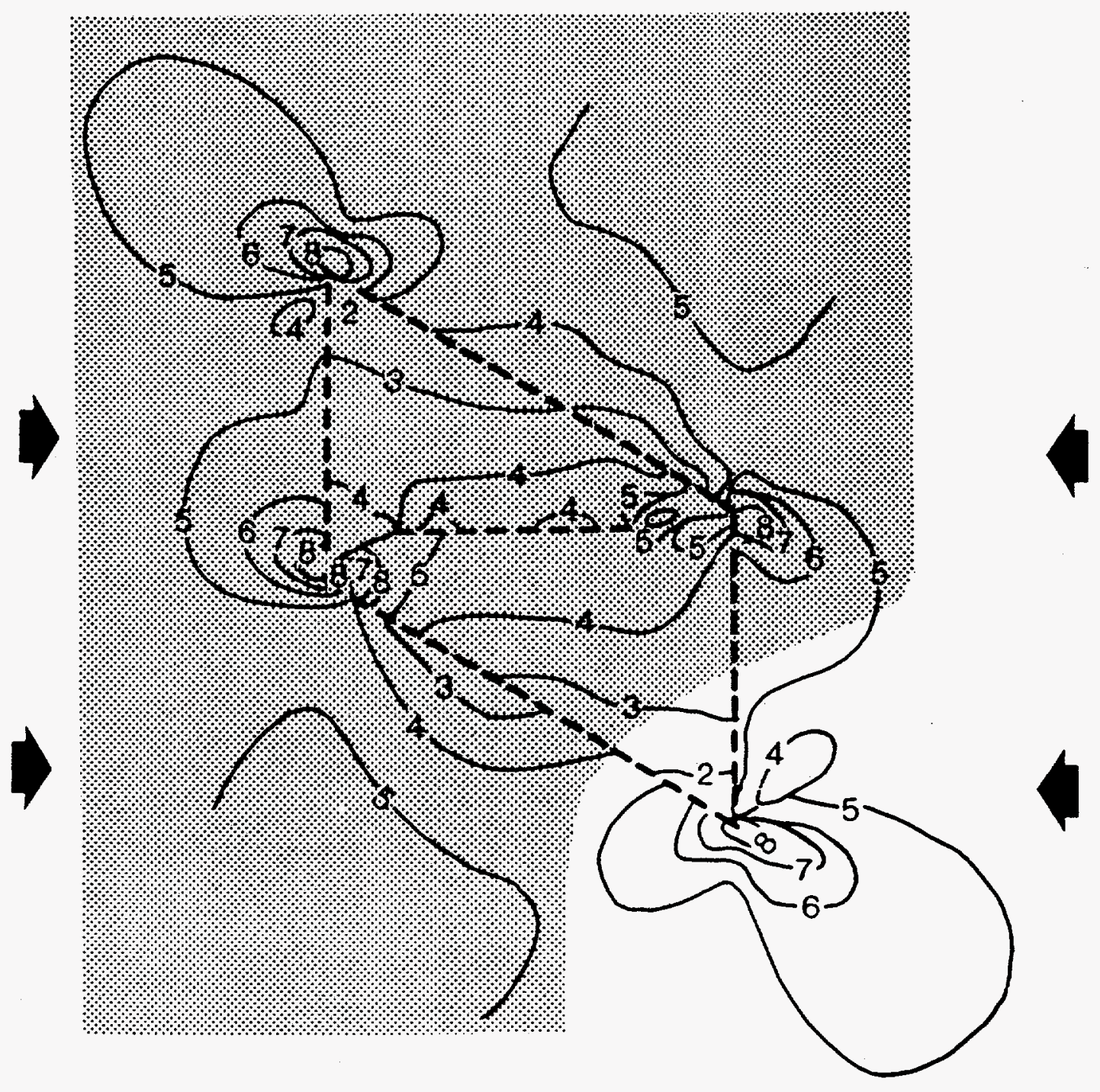

Figure 10. Stress distribution from a photoelastic experiment on intersecting fractures in rock under uniaxial loading (From Ma, et al., 1990). Regions at ends of fractures are locked. Numbered contours are presumed to represent isochromatic fringes of constant shear stress.

(Modified From Ellis, 1991). 


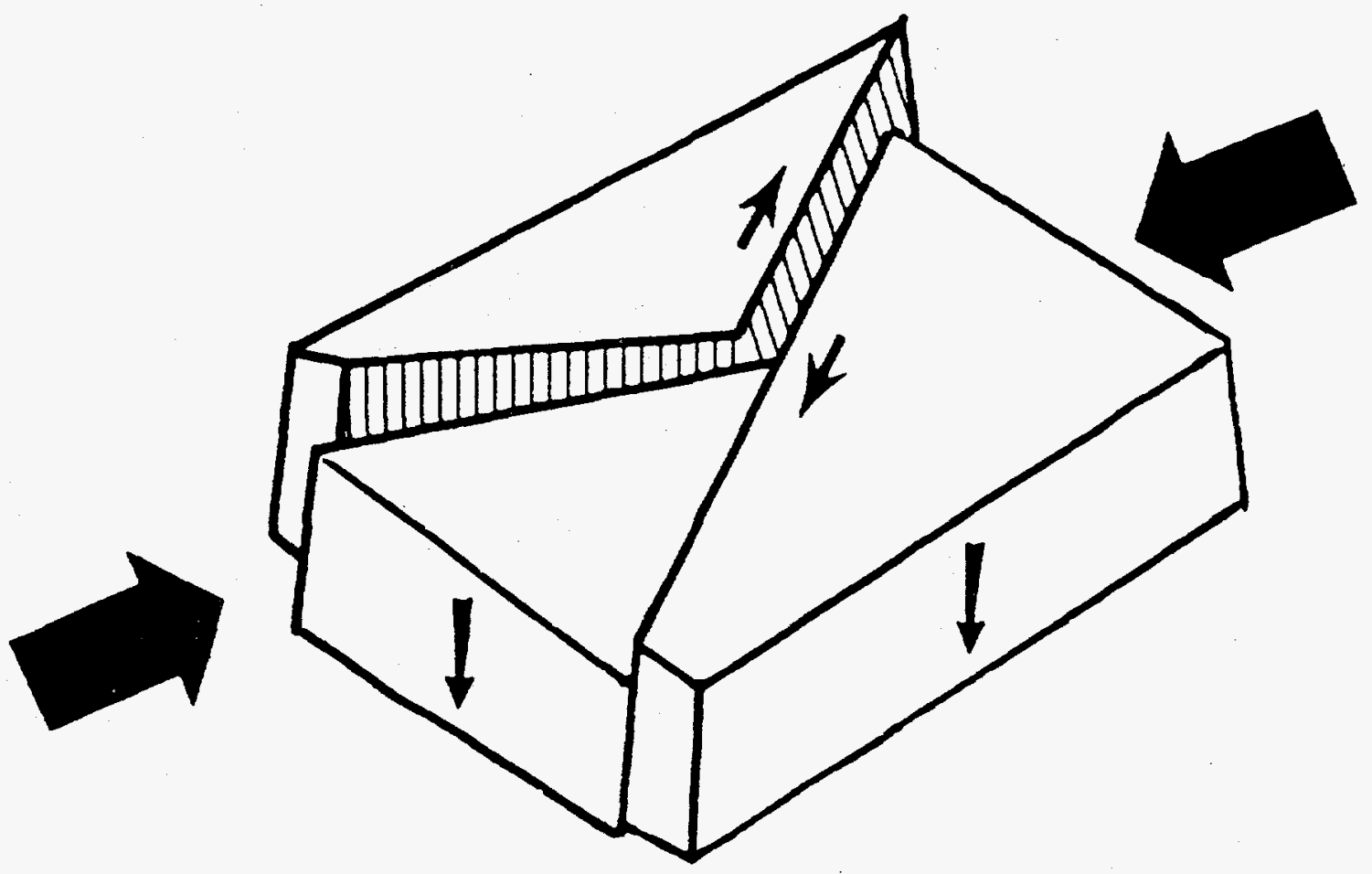

Figure 11. Schematic diagram showing the relative motion of blocks related to two intersecting faults. If the main fault undergoes strike slip motion, the adjoining block moves down due to kinematic adjustment. The large arrows represent the direction of $\mathrm{S}_{\mathrm{Hmax}}$.

(Modified From Talwani, 1988). 


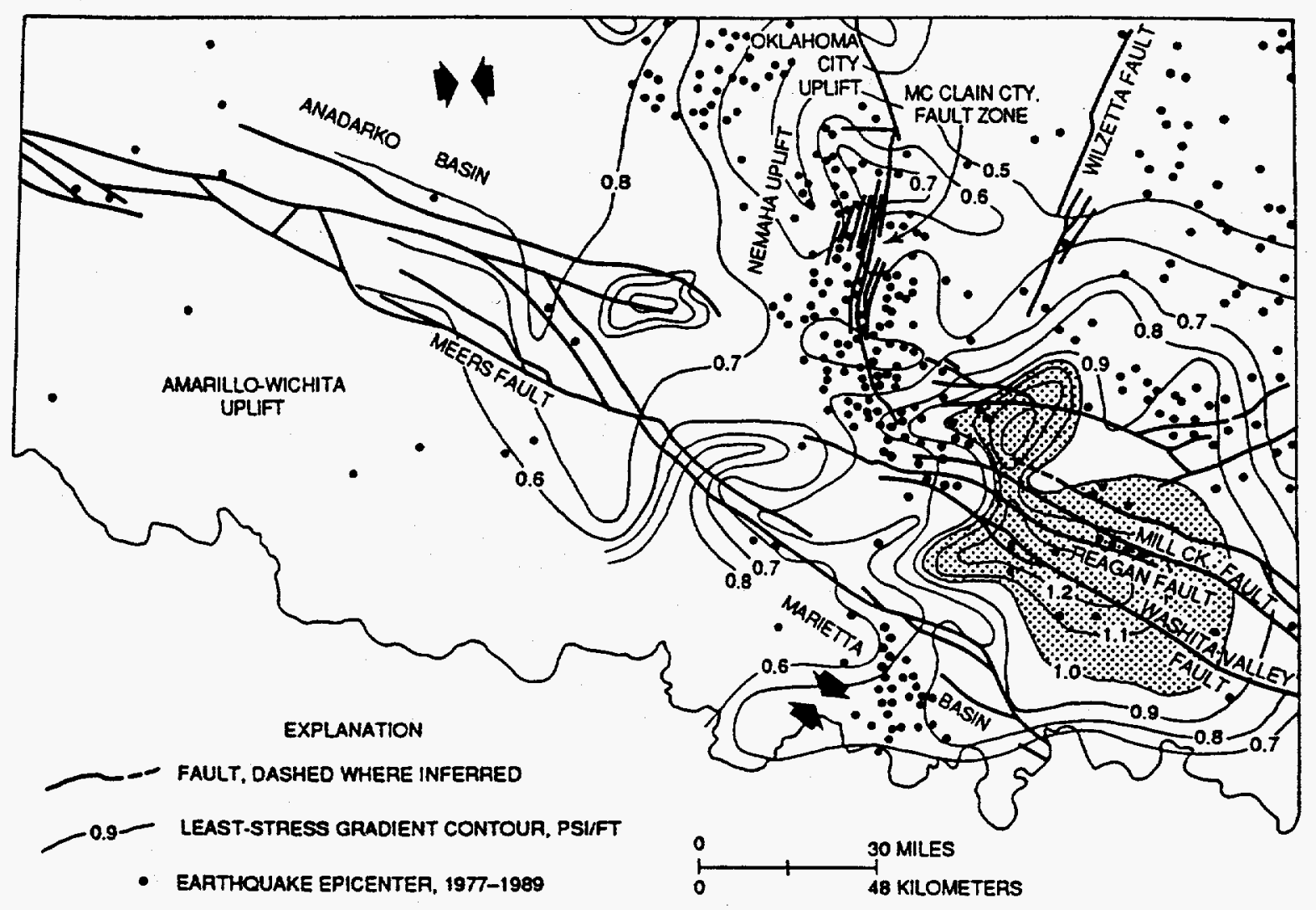

Figure 12. Least-stress gradient contour map for south-central Oklahoma showing major geologic features and the contemporary seismicity. Shaded area is where the least-stress gradient equals or exceeds 1.0 $\mathrm{psi} / \mathrm{ft}(0.023 \mathrm{MPa} / \mathrm{m})$. Solid arrows represent the average direction of $\mathrm{S}_{\mathrm{Hmax}}$ as inferred from borehole breakout data in the Anadarko basin and Marietta basin areas.

(Modified From Ellis, 1991). 
frontal fault system and the east flank of the Nemaha uplift are underlain by basement faults, indicating that these two fault systems are probably major linear zones of crustal weakness. The shape and location of the apparent high-stress zone relative to the intersection of the fault zones is similar to the zone of stress concentrations reported in a photoelastic study of intersecting rock fractures subjected to uniaxial loading ( $\mathrm{Ma}$, et al., 1990) (Figures 10 and 12). Compared to the surrounding region, a relatively large amount of contemporary seismicity occurs in an approximately $40 \mathrm{~km}$ wide by $135 \mathrm{~km}$ long zone that extends northward along the McClain County fault zone from near it's intersection with the Wichita frontal fault system. This spatial relationship between stress distribution, the intersection of major crustal fault zones, and contemporary seismicity is compatible in a qualitative sense with models for intraplate earthquakes in which intersecting zones of crustal weakness may be the foci of local stress concentrations."

\subsection{Localized Strain in the Mid-Lower Crust:}

Zoback (1983) and Zoback, et al., (1985) analyzed repeated triangulation measurements in southern New York and western Connecticut. They discovered the presence of localized anomalously high strain rates. In their model to explain the intraplate earthquakes, they propose that the high strain rates suggest the presence of localized ductile shear in the mid to lower crust below the seismogenic crust. This in turn could account for anomalously high rates of stress build-up in suitably located preexisting zones of weakness (Figure 13).

This model was based on the hypothesis previously discussed by Ratcliffe and others (Zoback, 1983). According to Zoback (1983), "there are preexisting ductile shear zones in the lower crust which concentrate deformation and thus concentrate stresses in the upper crust. Laboratory rock deformation evidence suggest that such zones could exist in the lower crust. As shown in Figure 13, theoretical studies show that such zones would cause localized areas of high stress in the brittle crust."

\subsection{Strain Measurement:}

In order to determine whether stresses are being concentrated and by what method these stresses are being focused, a two phase GPS campaign was planned. The first phase was carried out in December 1993 and January 1994 while the next phase will come in 5-7 years to compare intersite vectors. However, to obtain a first approximation of strain accumulation, combined GPS and preexisting triangulation datasets were used. Although combined datasets were used successfully in plate boundary regions, the successful use of triangulation data in 


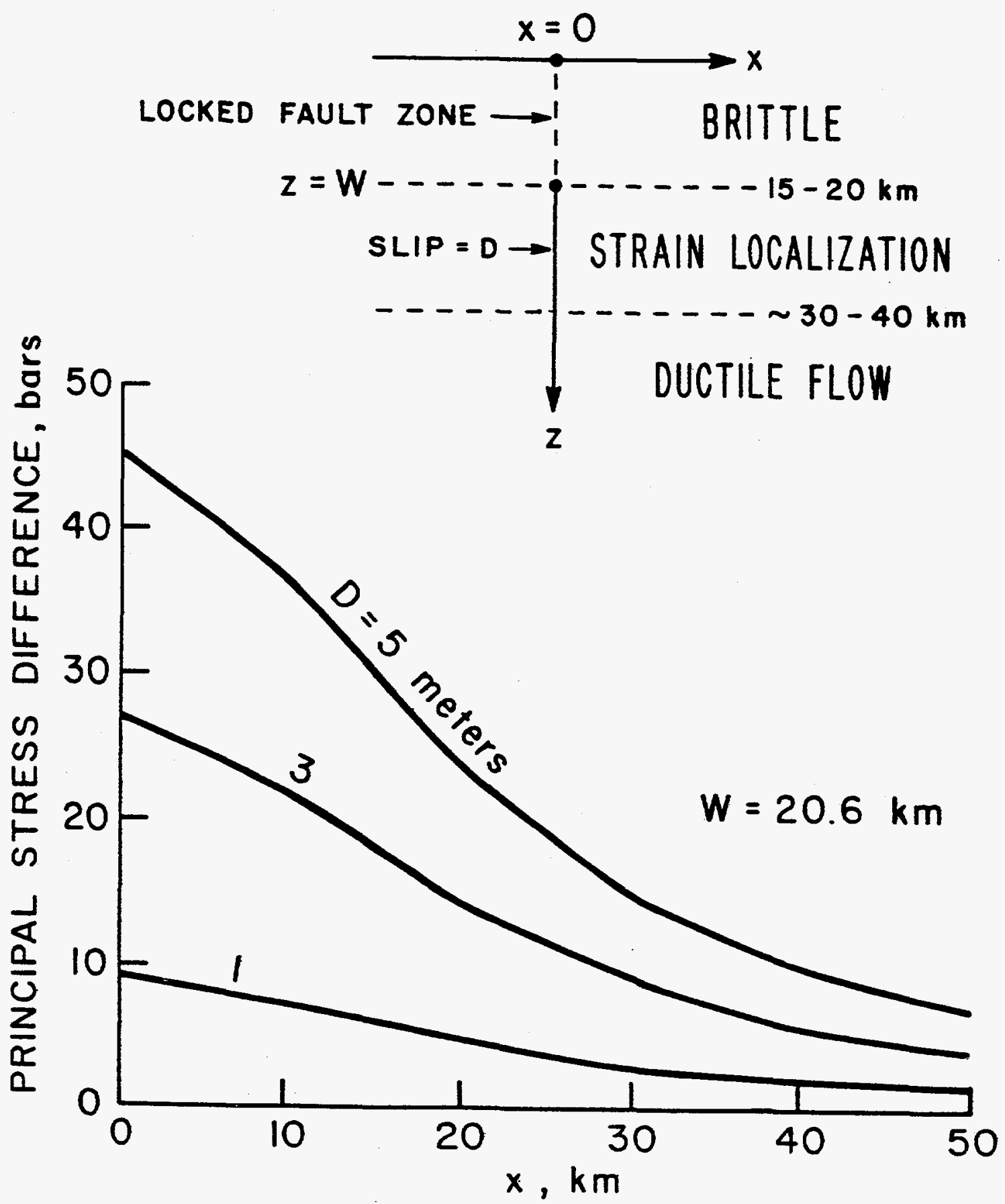

Figure 13. Model of a vertical strike slip fault in the upper crust which is driven by localized ductile strain in the lower crust.

(Modified From Zoback, et al., 1983). 
intraplate regions such as in southern New York (Zoback, et al., 1985) and New Madrid in Missouri (Liu, et al., 1992) (Liu, 1994) has been somewhat controversial. In southern New York the results have been disputed by a repeat analysis using more of the available data (Snay, 1986). Snay (1986) resolved that the result of a small representative sample with two suspect quality observations led to the high strain rates being estimated. After one was excluded and the other replaced, the resulting maximum shear rate was statistically indistinguishable from zero at $95 \%$ confidence level.

The need to measure the strain is significant in that the two models, the intersecting fault and lower crustal regional shear, are testable using geodetic techniques and if determined could help determine the site of other potential locations for large intraplate earthquakes. Leveling data suggest that the tectonic signal has a strain rate of about $10^{-7}$ per year. The intersection model would predict lobes of high stress near the intersection whereas the crustal strain model would predict a more elongate and longer wavelength distribution of increased strain rate.

To test these models, precise geodetic measurements with dense spatial sampling are required. The development of GPS as a geophysical tool has given us the ability to attempt to test the strain accumulation hypotheses. Previously attempts to measure strain in the Charleston area had not been undertaken due to the lack of repeat geodetic surveys in the area. Prescott, et al., (1985), using Frank's method, analyzed some repeated angles in South Carolina which admittedly were not in the vicinity of the 1886 Charleston earthquake. Analysis, after splitting the data into two groups, those near the seismic zone and those distant from the seismic zone, yielded values of strain rates that were not significantly different from zero at even one standard deviation.

\section{GPS Field Campaign:}

The use of the Global Positioning System (GPS) to determine stress concentrations as predicted by the two models and leveling data, requires measurement of various vectors between densely spaced measurement sites (intersite vectors) of varying orientations and magnitudes encompassing the proposed area of strain accumulation. A first attempt at satisfying these conditions entailed the establishment of an approximately 60 kilometer square grid centered at Middleton Place, the proposed area of fault intersection and the epicentral area of the 1886 Charleston earthquake while encompassing the area of suspected uplift to the southeast of Middleton Place (Poley and Talwani, 1986). With information supplied by Mr. Sid Miller and the staff of the South Carolina Geodetic Survey (SCGS), the locations of the 1930s triangulation and leveling line sites were plotted on the grid and acceptable first and second order sites were

NUREG/CR-6529 
chosen for inclusion in the GPS survey.

Unfortunately not all of the sites that were occupied in the 1930s are available nor are they all suitable for GPS measurements. Several factors can make a geodetic monument unsuitable for GPS observations. These include, destroyed station monuments due to the activities of man. Second and more importantly in areas like South Carolina, the growth of foliage and urbanization can lead to loss of line of site to the observed satellites. Finally, the existence of tall structures can lead to a syndrome known as multipath or reflection of the satellite signal which negates the use of the signal. After unrecoverable and unsuitable sites were eliminated, two compromises were instituted:

(1) A slight expansion of the grid to incorporate three quality, recoverable and suitable 1930s stations.

(2) The inclusion of several stations monumented in the 1980s expressly for GPS surveying.

Several more meetings with the staff at SCGS and much field checking led to an acceptable twenty station grid with good spread and alignment around Middleton Place (Figure 14). The stations were chosen with the anticipation of their reoccupation by GPS in the future. That would allow us to refine the strain measurements, as GPS precision continues to improve, as well as to compare with results obtained from a first approximation of strain rates using GPS/triangulation data (Figure 15).

Originally scheduled to begin December 1, 1993, the campaign was postponed due to equipment problems. Surveying was finally commenced on December 6, 1993 and continued until January 11, 1994. Eleven individual observation sessions averaging 6 hours in duration were scheduled to coincide with the time of day for the optimal satellite constellation geometry for measuring relative positions among the stations. All sessions were convened using 6 Trimble SST dual frequency receivers by the SCGS. The 11 observation days allowed for each station to be observed at least twice with two stations, Waltport and Sewee 2 RMA occupied continuously throughout the campaign (Figures 16, 17a and 17b). After the campaign the data were delivered to the USC by the SCGS for analysis.

\section{Data Analysis:}

All GPS data were processed using the JPL/NASA developed GIPSY-OASIS II (GPS Inferred Positioning System - Orbit Analysis and Simulation Software) software following a free orbit solution strategy developed by Jeffrey Freymueller which includes the scripts Front End and Solve. These two scripts call the 


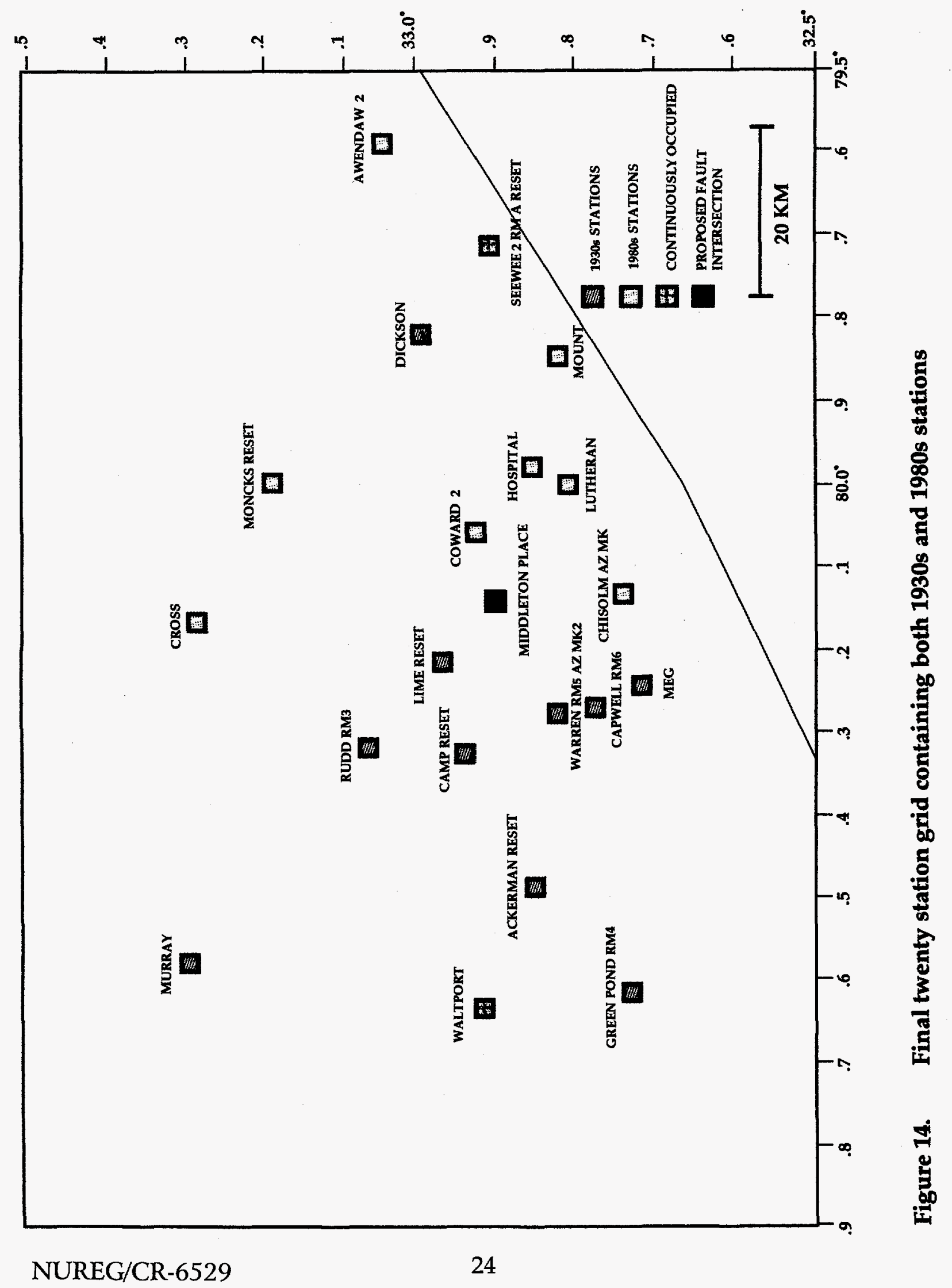




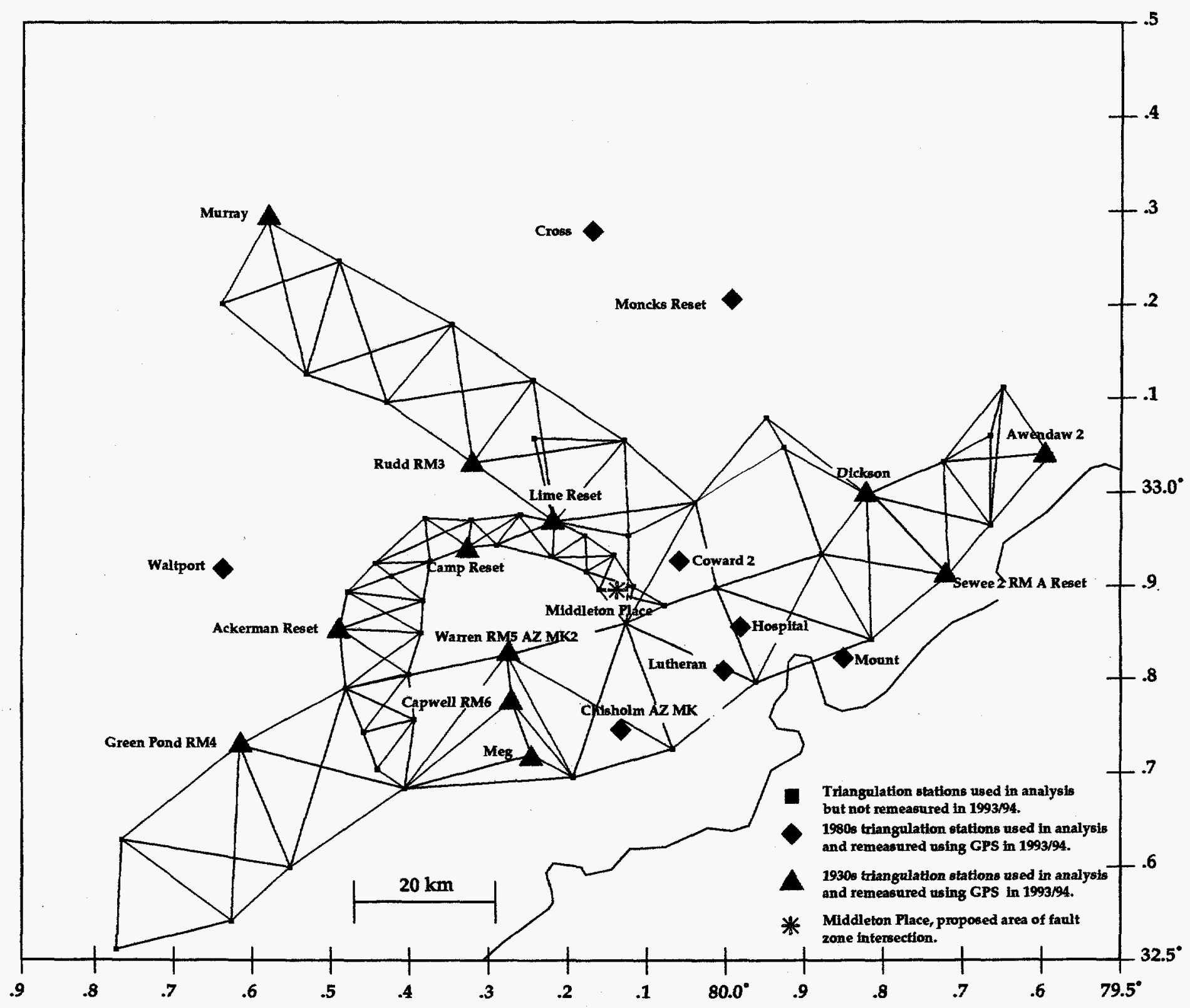

Figure 15. Triangulation and GPS network to be used in the strain analysis around Middleton Place. 


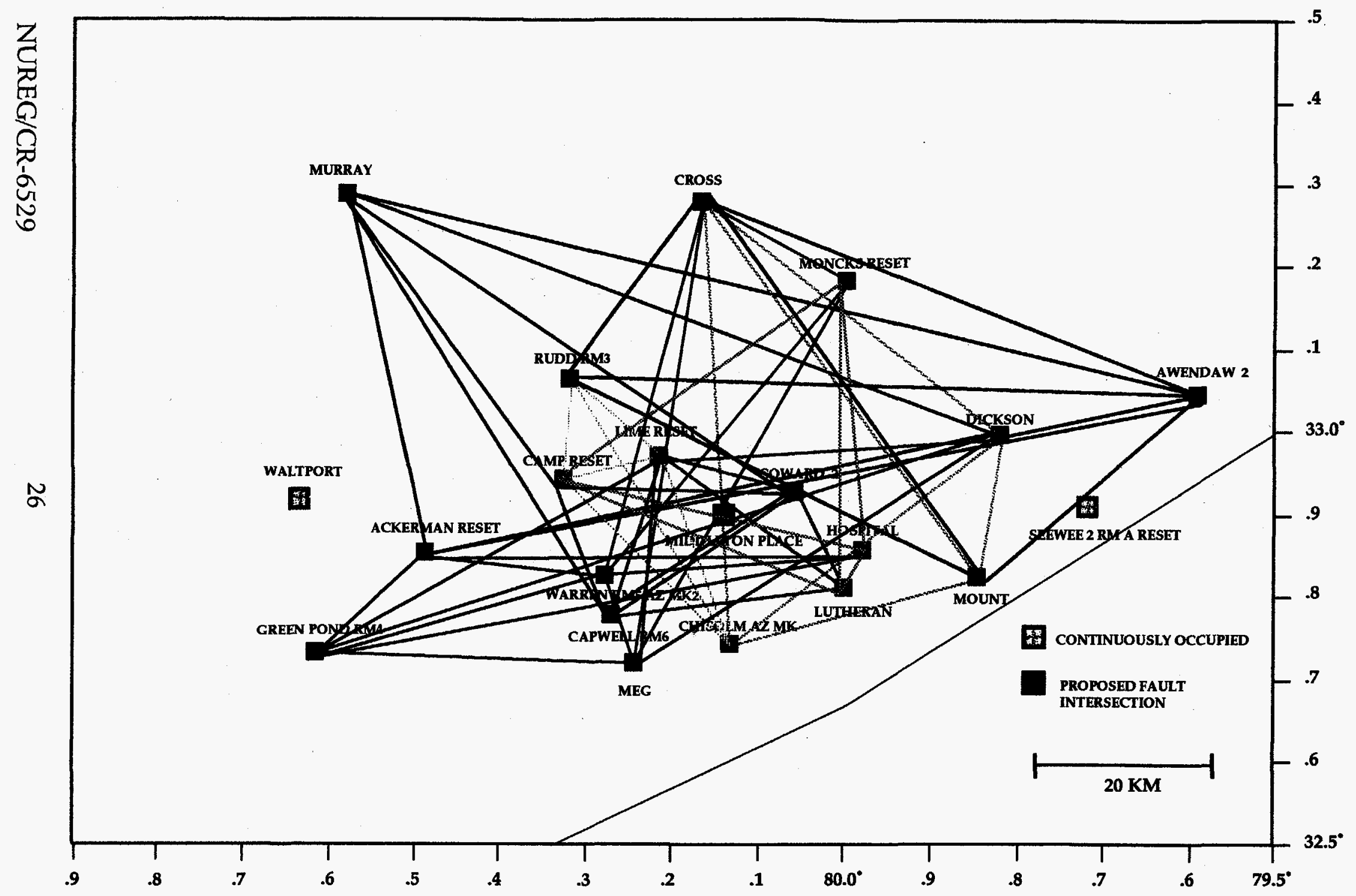

Figure 16. The total campaign: Each color represents one day of the campaign and shows baselines measured during that day. Baselines measured between continuously occupied stations and daily sessions are not displayed for clarity but it should be realized that these measurements add eight baseline measurements per session day and eighty baseline measurements throughout the campaign. 


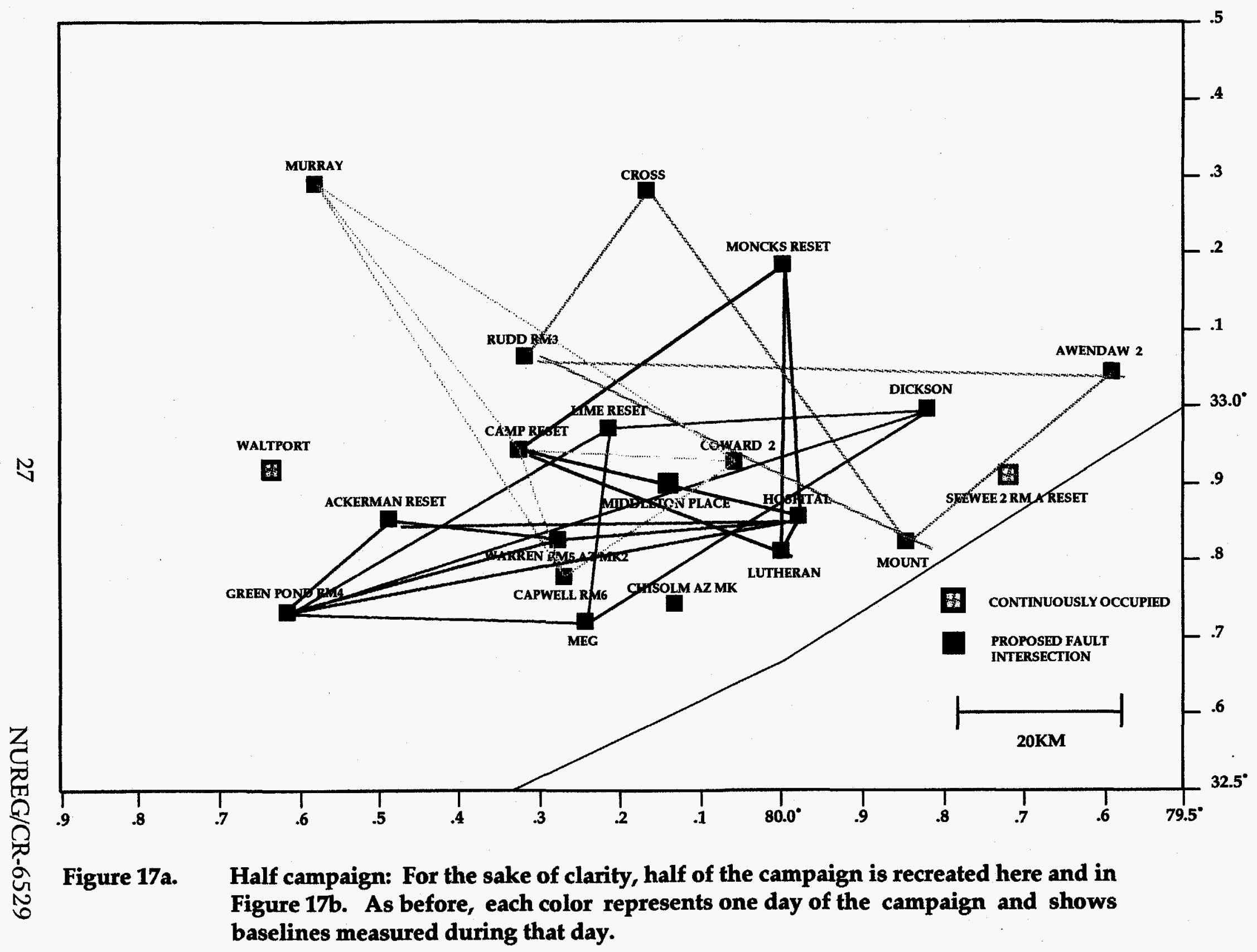




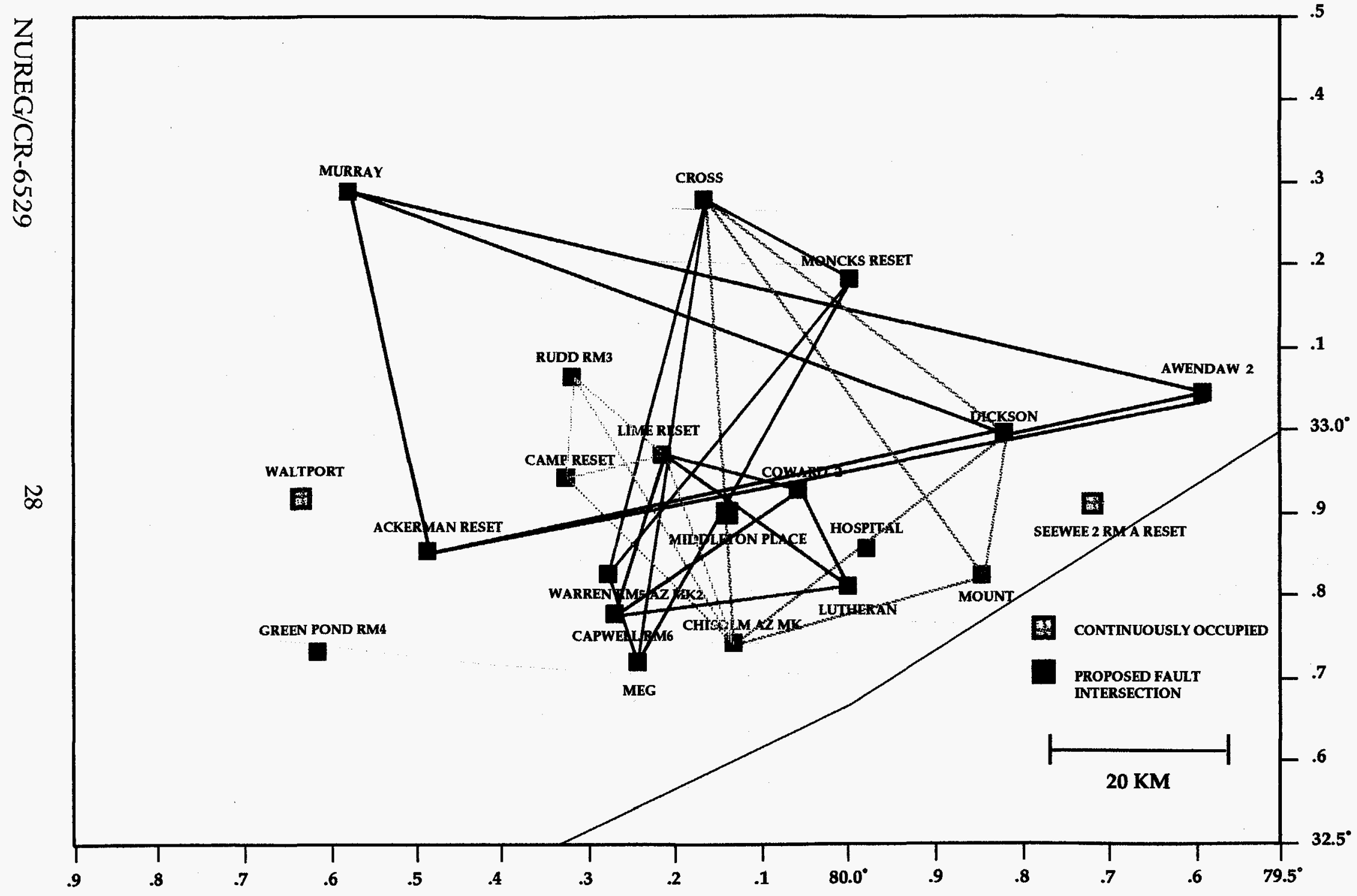

Figure 17b. Half campaign: For the sake of clarity, half of the campaign is recreated here and in Figure 17a. As before, each color represents one day of the campaign and shows baselines measured during that day. 
GIPSY-OASIS II modules as needed along with some preprocessing software written by Freymueller. A complete description of the processing scripts Front End and Solve is given in the Appendix.

For this project, the GPS phase data from the 11 observation sessions in combination produced 51 intersite vectors with appropriate covariance information among these vectors relative to one of the reference stations, Waltport, which was continuously occupied during the campaign (Figure 15). Each intersite vector $(\Delta X, \Delta Y, \Delta Z)$ represents the difference between the positional coordinates in an adopted cartesian reference system. (In this solution the International Terrestrial Reference Frame (ITRF92) was used). The data were processed using precise orbital information supplied by $10 \mathrm{JPL}$ tracking stations (Figure 18).

In order to estimate shear strain using data that are not repeatedly measured as is required when using Frank's method (Frank, 1966), the simultaneous reduction method (Bibby, 1982; Drew and Snay, 1989) was employed to calculate the maximum horizontal shear strain rate. A data processing software package using this method - DYNAP (DYNamic Adjustment Program) was developed by Drew and Snay (1989) through the modification of the ADJUST software package (Milbert and Kass, 1987). Like ADJUST, DYNAP accepts various geodetic data types to estimate 3 dimensional position coordinates for relevant geodetic stations. In addition, DYNAP enables the simultaneous estimation of several crustal dynamic parameters.

Formatting of data was an involved process as GIPSY-OASIS II (G-OII) format is not compatible with DYNAP. Briefly, the G-OII stacov files which contain the station coordinates and covariances had to be converted to Bernese (a similar software to G-OII developed at the University of Berne) output format using stacov2bern written by Freymueller. That output was altered to meet the naming and slightly different internal format used by COTODYN which was written by the scientists at UNAVCO (University NAVstar Consortium) and supplied by Chuck Meertens of UNAVCO. COTODYN takes Bernese formatted output and turns it into a format compatible with DYNAP.

Once the formatting was accomplished, the GPS data were adjusted using DYNAP in its non crustal parameter mode (ADJUST) and the solution covariance matrices were then scaled so that the weighted residual sum of squares divided by the number of degrees of freedom was 1.0. Data residuals from the network adjustment provide an indication of the internal precision $P$ defined as

$$
p=\left(\Sigma_{i=1}^{n} r_{i}^{2} / d f\right)^{.5}
$$




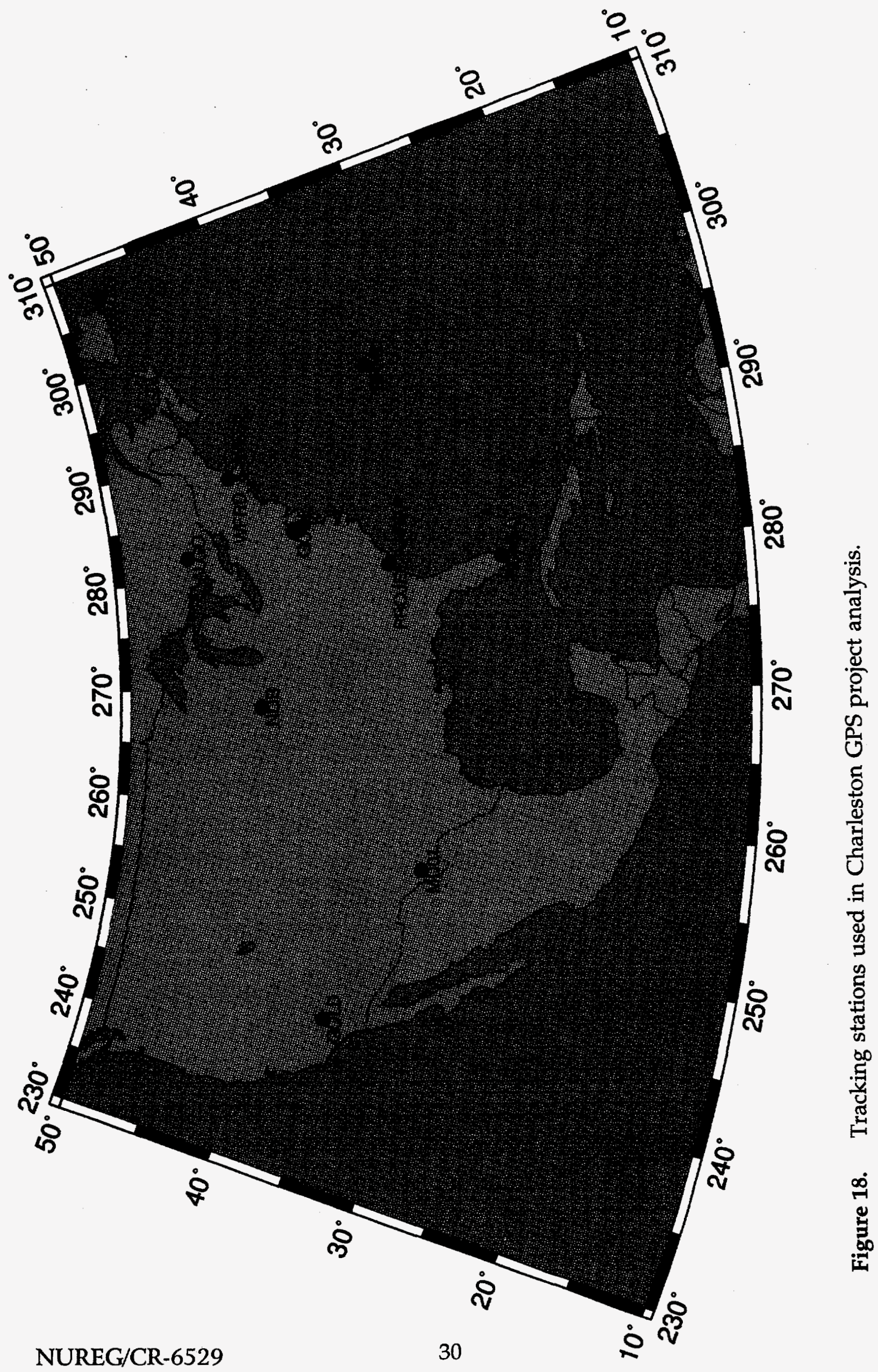


where $r_{i}$ denotes the $i$ th residual vector of one component and df denotes the degrees of freedom of this component of these vectors. In particular,

$$
\mathrm{df}=51(\text { vectors })-19(\text { stations })+1(\text { constraint })=33
$$

The constraint was imposed because intersite GPS vectors provide no information about absolute position. The N-S components of the 51 vectors have a precision $\mathrm{p}$ of $8 \mathrm{~mm}, \mathrm{E}-\mathrm{W}$ components have a precision of $4 \mathrm{~mm}$, and the vertical components have a precision of $4 \mathrm{~mm}$. Also because no information is provided about absolute position, the position (latitude and longitude) and the height of one station (Waltport) was specified and held fixed during the adjustment process. During the adjustment, one station, Lutheran was found to have residuals of more than one meter. This, of course, is unacceptable and the station was removed from the adjustment and from the dataset.

Distribution of residuals in each component (N-S, E-W, Vertical) as a function of intersite distance is given in Figure 19. Since each station was occupied at least twice, derived horizontal coordinates should have a precision better than $10 \mathrm{~mm}$ in each component relative to the fixed station, Waltport (Figure 15).

The National Geodetic Survey (NGS) supplied preexisting geodetic observations from their geodetic database for the area of the study located within the rectangular region bounded by latitudes $32.44^{\circ}$ and $33.18^{\circ} \mathrm{N}$ and longitudes $79.80^{\circ}$ and $80.39^{\circ} \mathrm{W}$ which encompasses the epicentral region of the 1886 Charleston earthquake. These data in contrast to the GPS coordinates will have a precision that is more than an order of magnitude worse.

After an adjustment of the preexisting geodetic data using DYNAP all questionable data and known blunders were removed. The questionable data are considered to be any observation that has a normalized residual of magnitude greater than 3.0 (Snay, Personal Communication, 1995), the two data sets are combined using 2 pieces of software provided by Richard Snay, COMBINE and CHBBOOK. The temporal distribution of this combined data set is given in Table 2 and the spatial distribution is shown in Figure 17. Most of these stations have been occupied only once revealing that the data for most of the geodetic stations contribute only indirectly toward the resolution of crustal deformation by providing network ties among the repeatedly observed geodetic stations (Snay, et al., 1992). Using DYNAP to process this combined dataset certain constraints were introduced to eliminate existing datum defects and configuration defects in the data. Since only the GPS station data provide height information, the heights of all non GPS stations are constrained to reported values by the geodetic survey and the tilt rate parameters in DYNAP were constrained to zero (Snay, Personal Communication, 1995). Again DYNAP was used to process the combined dataset but this time not only to generate least squares estimates for 


\section{Nortin - South Residwals}

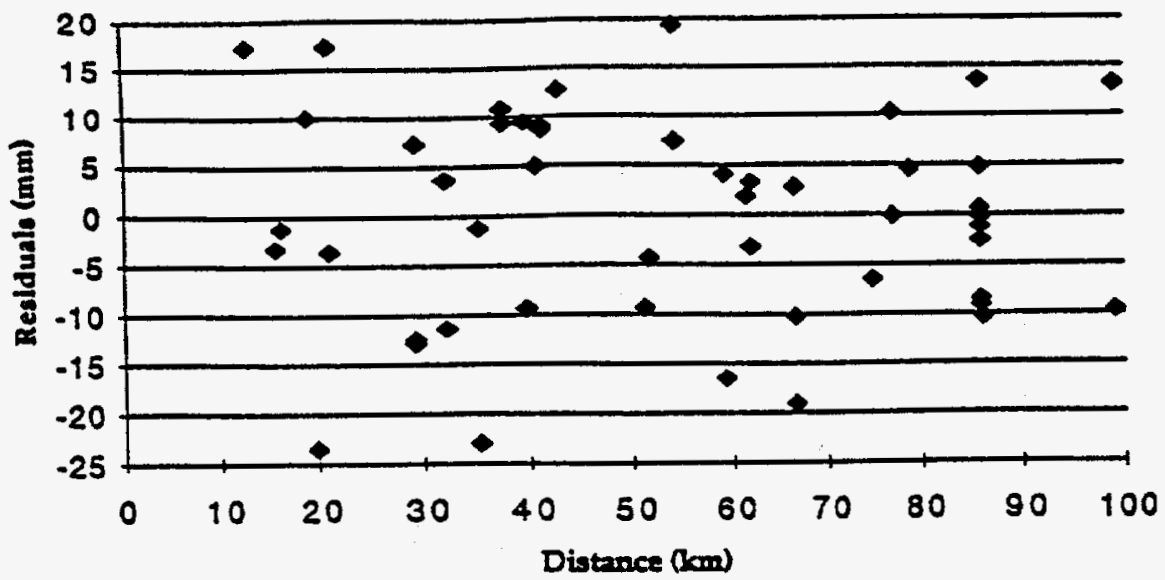

East - West Residuals

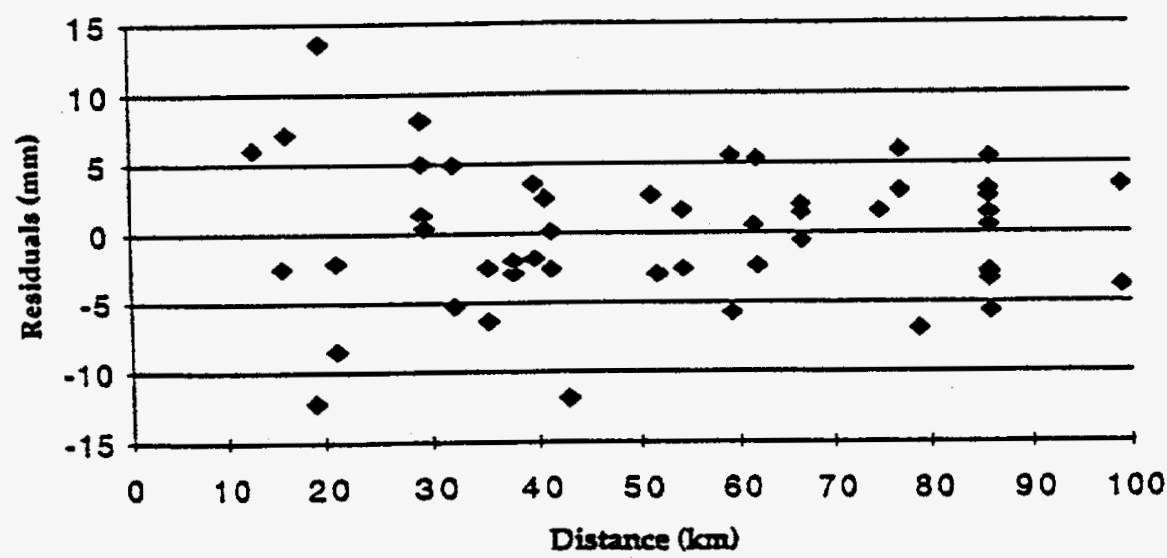

Vertical Residuals

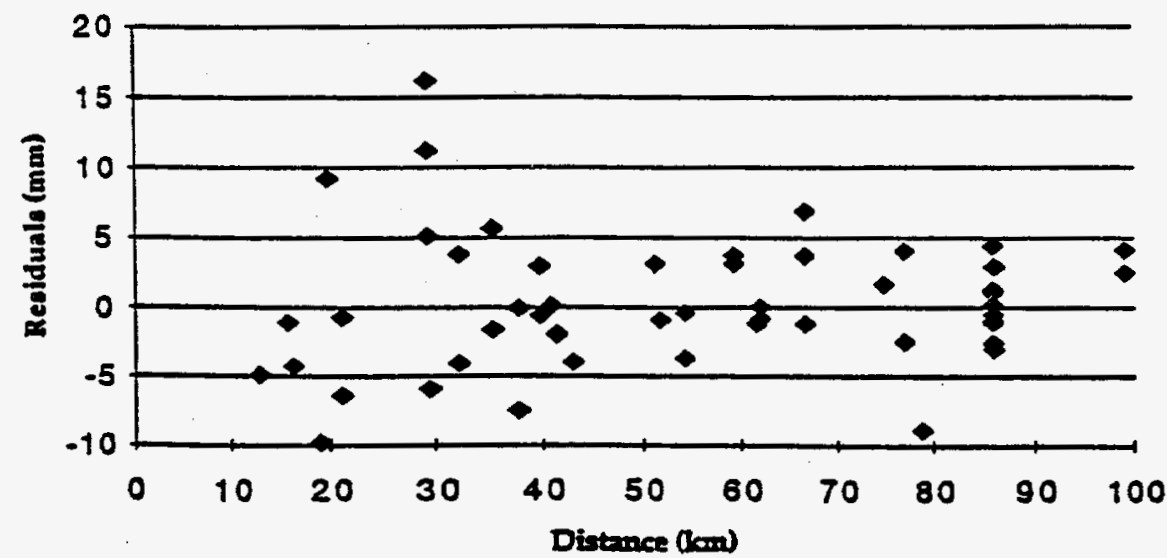

Figure 19. Residuals for intersite GPS vectors from a minimally constrained adjustment of these data. Residuals are plotted as a function of intersite distance from Waltport. 
the positional coordinates of the stations but also, simultaneously, for parameters that characterize crustal deformation rates. With the version of DYNAP employed, a spatially uniform and constant deformation rate during the 1924 - 1994 interval is assumed.

\section{Table 2.}

\section{Number of Observations by Decade}

\begin{tabular}{||c|c|c|c|c||}
\hline Interval & Directions & Distances & Azimuths & GPS Vectors \\
\hline $20-29$ & 533 & 10 & 1 & 0 \\
\hline $30-39$ & 1370 & 12 & 2 & 0 \\
\hline $40-49$ & 116 & 0 & 0 & 0 \\
\hline $50-59$ & 26 & 0 & 2 & 0 \\
\hline $60-69$ & 373 & 217 & 4 & 0 \\
\hline $70-79$ & 0 & 11 & 1 & 0 \\
\hline $80-89$ & 618 & 162 & 8 & 0 \\
\hline $89-94$ & 6 & 6 & 1 & 51 \\
\hline
\end{tabular}

Drew and Snay (1989) discuss the simultaneous reduction method at length and Snay, et al., (1992) summarize the mathematical conversion of the deformation parameters estimated by DYNAP into more familiar parameters. Of these parameters only those that characterize horizontal shear strain rates are resolved with a reasonable degree of accuracy. They summarize as follows. "These parameters are conventionally represented by the symbols $\dot{\gamma}_{1}$ and $\dot{\gamma}_{2}$, where $\dot{\gamma}_{1}$ denotes the rate of change of a right angle whose initial side is oriented $135^{\circ}$ and $\dot{\gamma}_{2}$ denotes the rate of change of a right angle whose initial side is oriented $90^{\circ}$. Here the right angles exist in a plane approximating the earth's surface and angles are reckoned positive in the clockwise direction. By virtue of the fact that deformation rates are here assumed to be spatially uniform, the deformation rate, $\alpha$, of any angle in the horizontal plane may be expressed by the equation

where

$$
\dot{\alpha}=\left(\operatorname{Sin} 2 \beta_{2}-\operatorname{Sin} 2 \beta_{1}\right) \dot{\gamma}_{1}+\left(\operatorname{Cos} 2 \beta_{2}-\operatorname{Cos} 2 \beta_{1}\right) \dot{\gamma}_{2}
$$


$B_{1}$ and $B_{2}$ denote the azimuths of the initial and terminal sides of the angle respectively. The parameters $\dot{\gamma}_{1}$ and $\dot{\gamma}_{2}$ may be further transformed into the parameters $\gamma$ and $\theta$ by the equations:

where

$$
\begin{gathered}
\dot{\gamma}=\left(\dot{\gamma}_{1}^{2}+\dot{\gamma}_{2}^{2}\right)^{.5} \\
\theta=0.5 \tan ^{-1}\left(-\dot{\gamma}_{2} / \dot{\gamma}_{1}\right)^{.5}
\end{gathered}
$$

$\dot{\gamma}$ denotes the maximum horizontal shear strain rate (that is, the magnitude for the rate of angular change that is greatest among all right angles in the horizontal plane and $\theta$ denotes the direction of maximum contraction (or equivalently, maximum extension) as measured clockwise from north.

\section{Results:}

Using the method described in Section 4 the shear strain rate in the epicentral region of the 1886 Charleston earthquake was estimated. The maximum shear rate $(\dot{\gamma})$ estimated by the simultaneous reduction method (DYNAP) equals $0.041 \pm$ $0.017 \mu$ strain /yr with a direction of maximum contraction $(\theta)$ equal to $66^{\circ} \pm 11^{\circ}$. The corresponding values of $\dot{\gamma}_{1}$ and $\dot{\gamma}_{2}$ are given in Table 3 .

Snay (1986) demonstrated that the bivariate hypothesis for the maximum shear to be non-zero at the $95 \%$ confidence level requires that the signal to noise ratio exceed 2.45. If the univariate hypothesis were used the signal to noise ratio would be 1.96 . However, if the univariate hypothesis were tested rather than the bivariate hypothesis faulty conclusions could be made because of the nonlinearity of the relation

$$
\dot{\gamma}=\left(\dot{\gamma}_{1}^{2}+\dot{\gamma}_{2}^{2}\right)^{.5}
$$

Therefore, using the value of 2.45 for estimating the $95 \%$ confidence ellipses of the shear strain rates, this estimate of $\dot{\gamma}$ does not differ significantly from zero.

\section{Discussion:}

Although the estimated strain rate is non-significant at the $95 \%$ confidence level, this rate would be distinguishably nonzero at a slightly lower confidence level. Since DYNAP gives only an average strain rate over the entire area of the survey, one possible explanation for the lack of significant deformation at the $95 \%$ confidence level is that the strain field is not uniform spatially as assumed 
by the process. Either significant strain in one subregion could cancel equally significant strain of opposite orientation in another sub region or the significant strain could be accumulating in one section of the study area and not in the others as suggested by the two models, Talwani (1988) and Zoback, et al., (1985). The cancellation by equal but oppositely oriented strain seems unlikely due to the consistency of the maximum contraction orientation $(\theta)$ with the reported orientation of $\mathrm{Sh}_{\max }$ as $60^{\circ} \mathrm{E}$ of N. (Talwani, 1982, 1984) (Zoback and Zoback, 1991) and the apparent consistency of the individual strain components (both $\gamma_{1}$ and $\gamma_{2}$ are both negative (contraction) and very similar in value). These consistencies and at a slightly lower confidence, statistically significant strain accumulation rate at values 3-4 orders of magnitude higher than the $1 \times 10^{-11}$ to $1 \times 10^{-12}$ average strain rate reported for the central and eastern North American plate and approximately 2 orders of magnitude higher than the $1 \times 10^{-9}$ average strain model predicted for the South Carolina - Georgia seismic zone (Anderson, 1986 ) and roughly $15 \%-20 \%$ of the average strain rate reported for the San Andreas Fault system (Thatcher, 1991) demand resolution of the stress focusing problem near Charleston.

Many methods have been used to test for spatial variability. Snay, et al., (1993) and Liu, et al., (1992) tested for spatial variability by breaking the study area into subregions and testing those subregions. Unfortunately the spacing and distribution of the available GPS sites does not lend itself readily to subdivision of the study area near Charleston. Only by repeating the GPS survey at some future date will we be able to resolve the question of stress concentration.

\section{Table 3.}

\section{Strain in ppm and Angle of Maximum Contraction Clockwise From North}

\begin{tabular}{|c|c|c|c|c|}
\hline Dataset & $\begin{array}{c}\dot{\gamma}_{1}=\dot{\varepsilon}_{\mathrm{EE}}-\dot{\varepsilon}_{\mathrm{NN}} \\
\mu \text { strain/year }\end{array}$ & $\begin{array}{c}\dot{\gamma}_{2}=\dot{\varepsilon}_{\mathrm{EN}}+\dot{\varepsilon}_{\mathrm{NE}} \\
\mu \text { strain/year }\end{array}$ & $\begin{array}{c}\dot{\gamma}=\left(\dot{\gamma}_{1}^{2}+\dot{\gamma}_{2}^{2}\right)^{.5} \\
\mu \text { strain/year }\end{array}$ & $\begin{array}{c}\theta=.5 \tan ^{-1}\left(-\dot{\gamma}_{2} / \dot{\gamma}_{1}\right)^{.5} \\
\text { degrees }\end{array}$ \\
\hline All Data & $-0.027 \pm 0.016$ & $-0.031 \pm 0.017$ & $0.041 \pm 0.017$ & $66^{\circ} \pm 11^{\circ}$ \\
\hline
\end{tabular}




\section{References}

Amick, D. and Gelinas, R., 1991. The Search for Evidence of Large Pre-historic Earthquakes Along the Atlantic Seaboard, Science, 251, 655-658.

Amick, D. and Talwani, P., 1986. Earthquake Recurrence Rates and Probability

Estimates for the Occurrence of Significant Seismic Activity in the Charleston Area: The Next 100 Years, in Proceedings of the Third U.S. National Conference on Earthquake Engineering, Vol. I, 55-64.

Anderson, J.G., 1986. Seismic Strain Rates in the Central and Eastern United States. Bull. Seismol. Soc. Am., 76, 273-290.

Andrews, D.J., 1989. Mechanics of Fault Junctions. J. Geophys. Res., 94, 93899397.

Barstow, N.L., Brill, K.G., Jr., Nuttli, O.W. and Pomeroy, P.W., 1981. An Approach to Seismic Zonation for Siting Nuclear Electric Power Generating Facilities in the Eastern United States, in NUREG/CR-1577, U.S. Nuclear Regulatory Commission.

Bibby, H.M., 1982. Unbiased Estimate of Strain From Triangulation Data Using the Method of Simultaneous Reduction. Tectonophysics, 82, 161-174.

Bollinger, G.A., 1972. Historical and Recent Seismic Activity in South Carolina. Bulletin of the Seismological Society of America, 62, 851-864.

Bollinger, G.A., 1975. A Catalog of Southern United States Earthquake - 1754 Through 1974. Virginia Polytechnical Institute and State University, Research Division Bulletin, 101, 68 pp.

Bollinger, G.A., 1977. Reinterpretation of the Intensity Data for the 1886 Charleston, South Carolina, Earthquake, in Rankin, D.W. (Editor), Studies Related to the Charleston, South Carolina, Earthquake of 1886 - A Preliminary Report: U.S. Geological Survey Professional Paper 1028, 17-32.

Bollinger, G.A., 1983. Speculations on the Nature of Seismicity at Charleston, South Carolina in Gohn, G.S. (Editor), Studies Related to the Charleston, South Carolina Earthquake of 1886 - Tectonics and Seismicity, U.S. Geological Survey Professional Paper 1313, T1-T11.

Bollinger, G.A. and Visvanathan, T.R., 1977. The Seismicity of South Carolina

Prior to 1886, in Rankin, D.W. (Editor), Studies Related to the Charleston, South Carolina, Earthquake of 1886 - A Preliminary Report: U.S. Geological Survey Professional Paper 1028, 33-42.

Bollinger, G.A., Johnston, A.C., Talwani, P., Long, L.T., Shedlock, K.M., Sibol, M.S. and Chapman, M.C., 1991. Seismicity of the Southeastern United States: 1698 to 1986, in Slemmons, D.B., Engdahl, E.R., Zoback, M.D. and Blackwell, D.D., (Editors),Neotectonics of North America: Boulder, Colorado, Geological Society of America, Decade Map, 1, 291-308.

Campbell, D.L., 1978. Investigation of the Concentration Mechanism for Intraplate Earthquakes. Geophys. Res. Lett., 5, 477-499. 
Drew, A.R. and Snay, R.A., 1989. DYNAP: Software for Estimating Crustal Deformation From Geodetic data. Tectonophysics, 162, 331-343.

Ellis, W.L., 1991. Stress Distribution in South Central Oklahoma and its Relationship to Crustal Structure and Contemporary Seismicity, in Roegiers, J-C (Editor), Proceedings of the 32nd U.S. Symposium on Rock Mechanics, 73-81.

Forsyth, D. and Uyeda, S., 1975. On the Relative Importance of the Forces of Plate Motion. Geophysical Journal of the Royal Astronomical Society, 43, 163-200.

Frank, F.C., 1966. Deduction of Earth Strains From Survey Data. Bull. Seismol. Soc.Am., 56, 35-42.

Illies, J. Henning, 1982. Der Hohenzollern Graben und IntraplattenSeismizität Infolge Vergitterung Lamellärer Scherung Mit Einer Riftstruktur. Oberrhein. Geol. Abh., 31, 47-78.

Johnston, A.C., 1989. The Seismicity of 'Stable Continental Interiors', in Earthquakes at North Atlantic Passive Margins: Neotectonics and Postglacial Rebound, S. Gregersen and P.W. Basham (Editors), Kluwer Academic Publishers, Dordrecht, Netherlands. 299-327.

Johnston, A.C., 1996. Seismic Moment Assessment of Stable Continental Earthquakes, Part 3: 1811-1812 New Madrid, 1886 Charleston and 1755 Lisbon. Submitted to Geophysical Journal International.

Kane, M.F., 1977. Correlation of Major Eastern Earthquake Centers with Mafic/Ultramafic Basement Masses, in Rankin, D.W. (Editor), Studies Related to the Charleston, South Carolina, Earthquake of 1886 - A Preliminary Report: U.S. Geological Survey Professional Paper 1028, 199-204.

King, G.C.P., 1986. Speculations on the Geometry of the Initiation and Termination Processes of Earthquake Rupture and its Relation to Morphological and Geological Structure. Pageoph, 124, 567-585.

King, G. and Nabelek, J., 1985. Role of Fault Bends in the Initiation and Termination of Earthquake Rupture. Science, 228, 984-987.

Kuang, Jian, Long, L.T. and Mareschal, J.C., 1989. Intraplate Seismicity and Stress in the Southeastern United States. Tectonophysics, 120, 29-42.

Kunze, A.W.G., 1982. Some Aspects of Viscous Stress Relaxation and Intraplate Seismicity. Tectonophysics, 82, T1 - T9.

Liu, L., 1994. Continental Seismotectonics: Stress, Strain and Strength. Ph.D. Thesis, Stanford University, $148 \mathrm{pp}$.

Liu, L., Zoback, M.D. and Segall, P., 1992. Rapid Intraplate Strain Accumulation in the New Madrid Seismic Zone. Science, 257, 1666-1669.

Long, L.T. and Champion, J.W., Jr., 1977. Bouguer Gravity Map of the Summerville-Charleston, South Carolina Epicentral Zone and Tectonic Implications, in Rankin, D.W., (Editor), Studies Related to the Charleston, South Carolina, Earthquake of 1886 - A Preliminary Report. U.S. Geological Survey Professional Paper 1028, 151-166. 
Long, L.T. and Zelt, K.H., 1991. A Local Weakening of the Brittle-Ductile Transition Can Explain Some Intraplate Seismic Zones. Tectonophysics, 186, 175-192.

Ma, Z., Fu, Z., Zhang, Y., Wang, C., Zhang, G. and Liu, D., 1990. Earthquake Prediction. Nine Major Earthquakes in China (1966-1976).

Madabhushi, S. and Talwani, P., 1993. Fault Plane Solutions and Relocations of Recent Earthquakes in Middleton Place Summerville Seismic Zone Near Charleston, South Carolina. Bull. Seism. Soc. Am., 83, 1442-1466.

Mareschal, J.C. and Kuang, J., 1987. Intraplate Stresses and Seismicity: The Role of Topography and Density Heterogeneities. Tectonophysics, 132, 153-162.

McGarr, A. and Gay, N.C., 1978. State of Stress in the Earth's Crust. Annual Reviews of Earth and Planetary Sciences, 6, 405-436.

McKeown, F.A., 1978. Hypothesis: Many Earthquakes in the Central and Southeastern United States are Causally Related to Mafic Intrusive Bodies. J. Res. U.S. Geological Survey, 6, 41-50.

Morgan, W.J., 1988. The Jubilee of Plate Tectonics (Summary of comments). EOS, Trans. Am. Geophys. U., 69, 584 pp.

Poley, C.M. and Talwani, P., 1986. Recent Vertical Crustal Movements Near Charleston, South Carolina. J. Geophys. Res., 91, 9055-9066.

Prescott, W.H., Krueger, S.W. and Zoback, M.D., 1985. Geodetic Constraints on Strain Rates in the Vicinity of the 1886 Charleston, South Carolina, Earthquake, in Proceedings of the First International Symposium on Precise Positioning with GPS, Rockville, Maryland, U.S. Department of Commerce, NOAA, NOS, II, 887-896.

Rhea, S., 1981. South Carolina Seismic Program, Seismological Data Report; Selected Events March 1973 - December 1977 and Network Events January 1978 - July 1980, in U.S. Geological Survey Open-File Report 81$0362,83 \mathrm{pp}$.

Richardson, R.M., Solomon, S.C. and Sleep, N.H., 1979. Tectonic Stress in the Plates. Rev. Geophys. Space Phys., 17, 981-1019.

Richardson, R.M. and Cox, B.L., 1984. Evolution of Oceanic Lithosphere: A Driving Force Study of the Nazca Plate. Journal of Geophysical Research, 89, 10,043-10,052.

Saucier, R.T., 1991. Geoarchaeological Evidence of Strong Prehistoric Earthquakes in the New Madrid (Missouri) Seismic Zone. Geology, 19, 296-298.

Simmons, G., Wang, R. and Illfelder, H., 1976. The Ossipee Mountains, New Hampshire: Earthquakes and a Stress Model, in Boston Edison Company, Pilgrim Unit 2. Report submitted to Nuclear Regulatory Commission pursuant to licensing of Pilgrim Unit 2, B1-1 to B1-15.

Snay, R.A., 1986. Horizontal Deformation in New York and Connecticut: Examining Contradictory Results From the Geodetic Evidence. Journal of Geophysical Research, 91, 12,695-12,702. 
Snay, R.A., Ni, J.F. and Neugebauer, H.C., 1993. Geodetically Derived Strain Across the Northern New Madrid Seismic Zone, in U.S. Geological Survey Professional Paper 1538, F1-F6.

Taber, S., 1914. Seismic Activity in the Atlantic Coastal Plain Near Charleston, South Carolina. Seismol. Soc. Bull., 4, 108-160.

Talwani, P., 1982. An Internally Consistent Pattern of Seismicity Near Charleston, South Carolina. Geology, 10, 654-658.

Talwani, P., 1984. Orientation of Stress in Southeastern U.S. (Abstract): Geological Society of America Abstracts with Programs, 16, 202 pp.

Talwani, P., 1985. Current Thoughts on the Cause of the Charleston, South Carolina Earthquakes. South Carolina Geology, 29, 19-38.

Talwani, P., 1986. Seismotectonics of the Charleston Region, In: Proceedings of the Third U.S. National Conference of the Earthquake Engineering Institute, 1, 15-24.

Talwani, P., 1988. The Intersection Model for Intraplate Earthquakes. Seismological Research Letters, 59, 305-310.

Talwani, P., 1989a. Characteristic Features of Intraplate Earthquakes and the Models Proposed to Explain Them, in Earthquakes at North-Atlantic Passive Margins: Neotectonics and Post-Glacial Rebound, S. Gregersen and P.W. Basham, (Editors), NATO ASI Series. Series C, Mathematical and Physical Sciences, 563-579.

Talwani, P., 1989b. Seismotectonics in the Southeastern United States, in Earthquakes at North-Atlantic Passive Margins: Neotectonics and PostGlacial Rebound, S. Gregersen and P.W. Basham, (Editors), NATO ASI Series. Series C, Mathematical and Physical Sciences, 371-392.

Talwani, P., Amick, D.C. and Logan, R., 1979. A Model to Explain the Intraplate Seismicity in the South Carolina Coastal Plain (Abstract). EOS,Trans.,Am. Geophy. Union, 60, $311 \mathrm{pp}$.

Talwani, P. and Amick, D.C., 1983. Summary of Discussion Group 1. Results and Role of Current Seismicity in Understanding the 1886 Charleston, South Carolina Earthquake. Moderator: Pradeep Talwani, in Hays, W.W. and Gori, P.L., (Editors), A Workshop on the 1886 Charleston, South Carolina Earthquakes and its Implications for Today. Proceedings of Conference: U.S. Geological Survey, Open File Report 83-843, 24-27.

Talwani, P. and Rajendran, K., 1991 . Some Seismological and Geometric Features of Intraplate Earthquakes. Tectonophysics, 186, 19-41.

Talwani, P., Trenkamp, R. and Cannon, R., 1995. South Carolina Seismic Network Bulletin, IV, 1994, 39 pp.

Tarr, A.C., 1977. Recent Seismicity Near Charleston, South Carolina and its Relationship to the August 31, 1886 Earthquake, in Rankin, D.W., (Editor), Studies Related to the Charleston, South Carolina, Earthquake of 1886 - A Preliminary Report, U.S. Geological Survey Professional Paper 1028, 4357. 
Tarr, A.C. and King, K.W., 1974. South Carolina Seismic Program, in U.S. Geological Survey Open File Report, 74-58, 15 pp.

Tarr, A.C., Talwani, P., Rhea, S., Carver, D. and Amick D., 1981. Results of Recent South Carolina Seismological Studies. Bull. Seismol. Soc. Am., 71, 1883-1902.

Thatcher, W., 1991. Present-day Crustal Movements and the Mechanics of Cyclic Deformation, in U.S. Geological Survey Professional Paper, 1515, 189-205.

Visvanathan, T.R., 1980. Earthquakes in South Carolina, 1698-1975, in South Carolina Geological Survey Bulletin, 40,61 pp.

Zoback, M.D., 1983. Intraplate Earthquakes, Crustal Deformation and in situ Stress, in Hays, W.W. and Gori, P.L., (Editors), A Workshop on the 1886 Charleston, South Carolina Earthquakes and its Implications for Today. Proceedings of Conference: U.S. Geological Survey, Open File Report 83-843, 169-178.

Zoback, M.L., 1992. First-and Second-Order Patterns of Stress in the Lithosphere: The World Stress Map Project. Journal of Geophysical Research, 97, 11,703-11,728.

Zoback, D. and Zoback, M.L., 1991. Tectonic Stress Field of North America and Relative Plate Motions, in Slemmons, D.B., Engdahl, E.R., Zoback, M.D. and Blackwell, D.D., (Editors), Neotectonics of North America: Boulder, Colorado, Geological Society of America, Decade Map, 1, 339-366.

Zoback, M.D., Prescott, W.H., and Krueger, S.W., 1985. Evidence for Lower Crustal Ductile Strain Localization in Southern New York. Nature, 317, 705-707.

Zoback, M.L., Zoback, M.D., Adams, J., Assumpcão, Bell, S., Bergman, E.A., Blümling, P., Brereton, N.R., Denham, J.D., Fuchs, K., Gay, N., Gregersen, S., Gupta, H.K., Gvishiani, A., Jacob, K., Klein, R., Knoll, P., Magee, M., Mercier, J.L., Müller, B.C., Paquin, C., Rajendran, K., Stephansson, O., Suarez, G., Suter, M., Udias, A., Xu, Z.H. and Zhizhin, M., 1989. Global Patterns of Tectonic Stress. Nature, 341, 291-298. 


\section{Appendix}

\section{Solution Strategy Developed by Jeff Freymueller for GPS Data Processing Using GIPSY-OASIS II Software}

The solution strategy entails the taking the RINEX (Receiver INdependent Exchange format) data which are created from the raw receiver data and running Front-End, a script written by Jeff Freymueller which ultimately creates the quick measurement (qm) (GIPSY binary internal format) files. Front-End uses four individual programs to produce the internal format files. These are: (1) PhaseEdit or TurboEdit which are automatic data editing programs used to detect and fix cycle slips, if possible, or flag them if unfixable. Different receiver types require the different editing algorithms. (2) Clockprep which corrects the time tag offsets introduced by the rinex conversion programs for Trimble receivers in order to produce a physically consistent set of observables. (3) Ninja which decimates the data to a user specified time interval and after all satellites have been processed, the data are merged and time ordered for output to a quick measurement file. (4) OI is the orbit integration software for GIPSY and computes the spacecraft orbits. Starting from prescribed initial conditions and after specifying the participating force models and their parameters, OI will integrate the spacecraft dynamic equation and will generate an orbit that is sufficiently accurate. Next the Solve script is run to compute the geodetic parameters of interest using some several programs. They are Mergqm which merges all of the separate qm files for a single observation day into a single qm file for input into Qregres. Qregres computes a model of the observables and partial derivatives and then linearizes the model about the 'a priori value of the station coordinates, satellite orbits and other model parameters. Two prefilter programs Preprefilter and Prefilter prepare the data for Filter which is the estimation program. It uses the Square Root Information Factorized Kalman Filter (SRIF) with the capability of estimating time varying (stochastic) parameters as well as standard (constant) parameters. Smapper is the smoother step of the Kalman Filter and is required to obtain estimates of time varying parameters which are based on all the data. Postfit computes the postfit residuals and applies a user specified tolerance to each residual. Any larger residuals are flagged as outliers. And finally Stacov creates the ascii station coordinates and covariances file. After all the automatic editing has finished a visual analysis of individual station - satellite pairs using Postplot is necessary to clean up any lingering problems. 


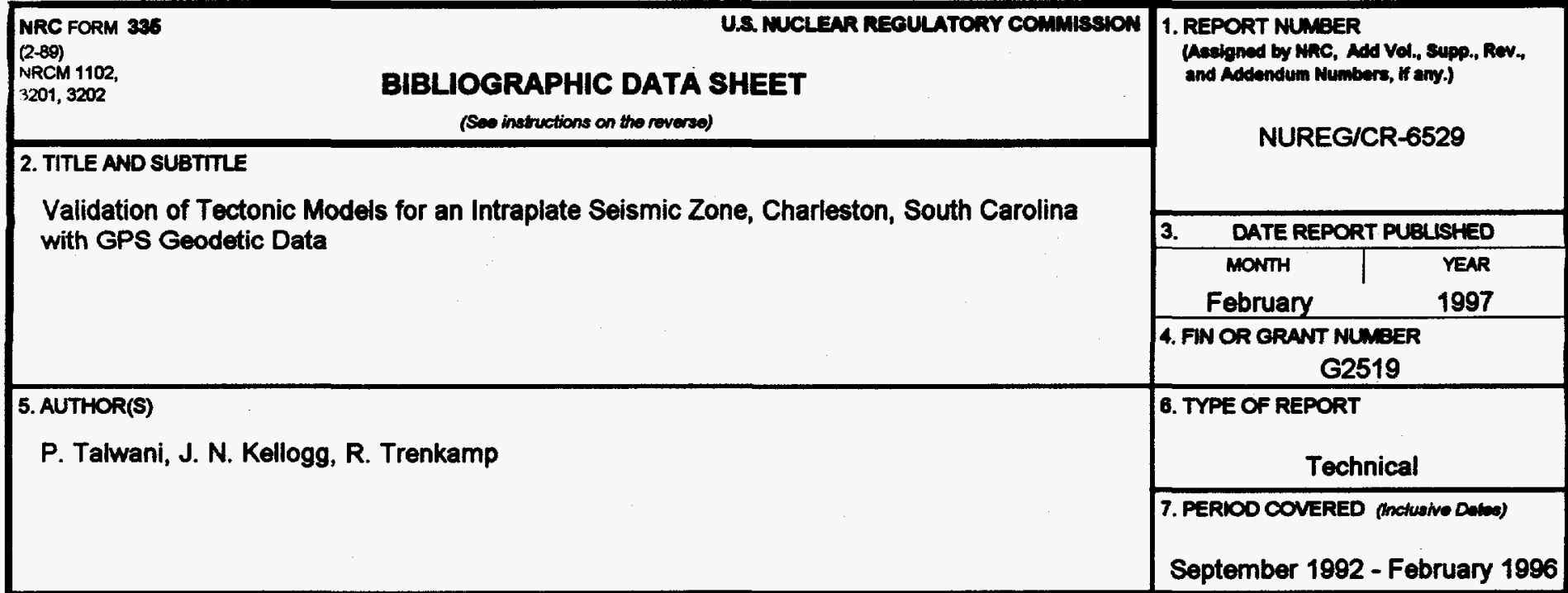

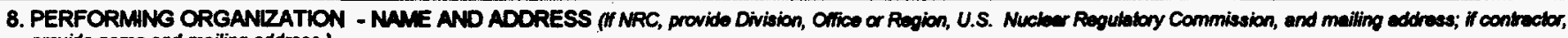
provide nams and moiling eddrocs.)

University of South Carolina

Department of Geological Sciences

Columbia, SC 29208

9. SPONSORING ORGANIZATION - NAME AND ADDRESS (F NRC, type "Same as above"; if contractor, provide NRC Division, Office or Region, U.S. Nucioer Regulatory Commiasion, and meiling address.)

Division of Engineering Technology

Office of Nuclear Regulatory Research

U.S. Nuclear Regulatory Commission

Washington, DC 20555-0001

10. SUPPLEMENTARY NOTES

E. G. Zurflueh, NRC Project Manager

11. ABSTRACT noo words or loses)

Alt' inugh the average strain rate in intrapiate settings is 2-3 orders of magnitude lower

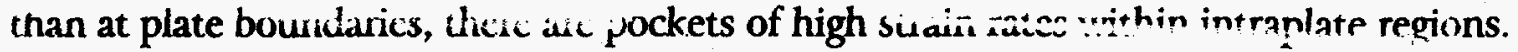

The results of a Global Positioning System survey near the location of current seismicity (and the inferred location of the destructive 1886 Charleston, South Carolina earthquake) suggest that there is anomalous strain build-up occurring there. By reoccupying 1930 triangulation and 1980 GPS sites with six Trimble SST dual frequency receivers, a strain rate of $0.4 \times 10^{-7} \mathrm{yr}^{-1}$ was observed. At the $95 \%$ confidence level, this value is not significant; however, at a lower level of confidence $(\sim 85 \%)$ it is about two orders of magnitude greater than the background of $10^{-9}$ to $10^{-10} \mathrm{yr}^{-1}$. The direction of contraction inferred from the GPS survey $66^{\circ} \pm 11^{\circ}$ is in excellent ggreement with the direction of the maximum horizontal stress $\left(\mathrm{N} 60^{\circ} \mathrm{E}\right)$ in the area, suggesting that the observed strain rate is also real.

12. KEY WORDSIDESCRIPTORS Riat words or phrases thet will assist rosewrehers in locating the report.)

GPS

Crustal Strain

Charleston

South Carolina

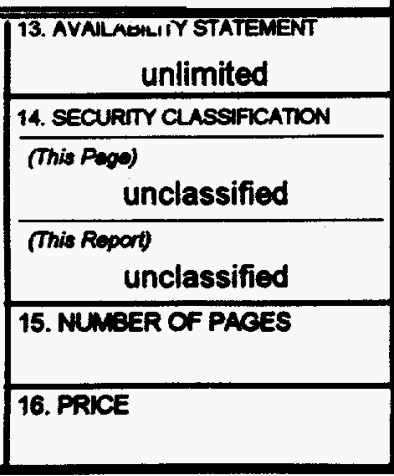

